\title{
Synchronous Leisure, Jointness and Household Labor Supply*
}

\author{
Daniel Hallberg ${ }^{\dagger}$
}

May 15, 2002

\begin{abstract}
This paper examines the synchronous leisure of spouses and the extent to which spouses spend time together. The time budget data set used in this paper allows for a distinction between simultaneous time-use of spouses and the actual time that spouses meet. A comparison between couples and matched singles suggests that only about 12 percent ( 45 minutes per day) of the synchronous leisure is caused by active synchronization. Spouses' decisions about market work and leisure timing are very interdependent during most hours of the day. The results also suggest that, conditional on synchronous leisure, parents with high incomes spend more time together than others, while more educated people allocating less time to their spouses.
\end{abstract}

Keywords: Time-use, synchronous leisure, working hours, togetherness, family economics, statistical matching.

JEL Classification: D1, J22.

\footnotetext{
*I would like to thank Anders Klevmarken, Henry Ohlsson, Magnus Wikström and Per Johansson for helpful comments and suggestions.

${ }^{\dagger}$ Department of Economics, Uppsala University, P.O. Box 513, SE-751 20 Uppsala, Sweden, Daniel.Hallberg@nek.uu.se.
} 


\section{Introduction}

The most important factor influencing peoples' timing of daily activities might be how others time their activities. It is, for instance, reasonable to believe that spouses want to synchronize their individual timing of market work and leisure so that they can spend more time together. Naturally, individuals and households would maximize utility with respect to synchronized leisure consumption, because spending time together is central for making relationships and families work. We would believe that subjects of rejoice and distress, but also work effort in ordinary household duties and enjoyment of leisure activities, involve elements of timing. The coordination and timing of work effort is also important, and sometimes essential, in many workplaces.

The interaction between household members and how they optimize their joint time-use (e.g. the labor supply of spouses) has been and still is a subject for economic research (see Killingsworth and Heckman, 1986, for a survey on female labor supply). However, while the traditional time allocation model typically studies the total time spent in, e.g., market work, over a day or a week, it provides little or no insight into the temporal pattern of timeuse and therefore, potentially, misses a vital part of the mechanisms underlying empirical observations. The total time spent in leisure (or market work) may not be the (only) relevant choice for individuals. If couples seek to enjoy more time together and therefore interact to synchronize the timing of work and leisure, it seems more relevant to analyze the temporal pattern of time-use than to just analyze the total time spent in market work and leisure during a day or a week.

This study is important for a number of reasons. Depending on whether parents with small children choose to have synchronous working schedules, they will have different demands for public child care. Neglecting the timing aspect of time-use and the interaction between spouses may cause biased estimates of the economic incentives for labor supply and when it is performed. Heterogeneity between spouses and between households in working schedule arrangements and restrictions in choosing the optimal work schedule are normally not part of the traditional time allocation model. This should affect our conception of wel- 
fare, if we think it depends on the extent to which members in a society can interact. ${ }^{1}$

Few (economic) studies have examined the temporal choice of time-use, and time budget data sets are underutilized in this respect. ${ }^{2}$ Among the exceptions are Hamermesh (1998, 1999, 2000), who studied the contemporaneous leisure of spouses and whether they choose working hours in order to enjoy more synchronous leisure. One finding was that work schedules of husbands and wives were in fact interdependent during most hours of the day. If one spouse was at work at a specific hour, the other was more likely to be so than not. He also found that couples with higher earnings (holding total market work hours constant) consume more synchronous leisure. This implies that synchronous leisure might be considered a normal good. Hamermesh (1999) argued that the decline in work at odd hours between the 1970s and the 1990s in the US did not depend on an industrial shift or changes in demography. This pattern might well be explained by the fact that workers are economically better off and therefore need not choose inconvenient working hours. Velzen (2001) studied the timing aspects of work and leisure of Dutch two-earner households and her main findings match those of Hamermesh (2000). On average, Dutch husbands and wives mostly tend to work and enjoy leisure at the same time of the day, and more so if household work was included in the definition of work and leisure was analyzed as a separate category. An interesting result can be found in Rydenstam and Wadeskog (1995), suggesting that

\footnotetext{
${ }^{1}$ It is characteristic of the Swedish labor market that men in general have better possibilities to organize their working time than women and that men's power to alter working hours increase with age, while no such pattern was found for women (SCB, 1999). 37 percent and 46 percent of the working men and working women, respectively, stated that they could not vary their working schedule. The survey (SCB, 1999) also showed that working nights was more common among women than men and about uniformly distributed over different age-groups, while men more frequently took up shift work than women. Shift work tended to decrease with age, and it was, therefore, mainly men below their 50s that worked in shifts. At the same time, it seems that men had a slightly more unregulated working schedule as compared to women; 9 percent (5 percent) of all males (females) reported that they work overtime every day and 24 percent (28 percent) of the males (females) reported that they rarely work overtime.

2 Issues of instantaneous timing have been discussed in sociology (see, e.g., Sullivan, 1996, for some empirical work on the evaluation of activities undertaken alone or with someone else). For an early discussion on collective rhythms in a family context, see Moore (1963). Kooreman and Wunderink (1996) suggested arguments against a collective rhythm. More flexible time schedules allow individuals time sovereignty and a more efficiency use of time and space.
} 
unoccupied time away from market work was more fragmentary for women as compared to men. An interpretation would be that the time allocation of women is more interconnected, and partly directed by, the demands of household work. While men enjoy their leisure in long sequences without interruption, women enjoy theirs in shorter fragments.

Hallberg and Klevmarken (2002) suggested that Swedish families where both parents work seem to have a tight schedule. Parents were more likely to cut down on their own private time than reducing the time with their children. However, the need to provide child care (at home) may not only lead a couple to alter their total supply of labor but also the timing of market work and leisure, thus potentially affecting spouses possibilities to enjoy synchronously leisure. Hamermesh (2000) suggested that having new children implied a reduction in synchronous leisure and that the impact was greatest among first-time parents. New mothers also changed their working schedules the most as compared to other groups. Velzen (2001) also found that the presence of fairly young children had a negative impact on the degree of synchronization of work and leisure schedules.

This paper offers empirical evidence for Sweden on the temporal pattern of various activities, including when market work is performed, and on the nature of synchronous leisure consumption. Hamermesh's (2000) hypothesis was that spouses adjusted their working schedules in order to enjoy more synchronized leisure. The traditional time allocation model is therefore usually incorrect, since it does not take the temporal aspect of time-use into account. It is, however, problematic to test this hypothesis just by studying the correlation in the timing of activities of spouses. The problem arises since we do not know to what extent the observed outcome in timing is a result of the proposed timing adjustment or an effect of the general organization in society, respectively. There are, for example, social and biological rhythms of daily life of society that are important for the timing of most people. ${ }^{3}$

The contributions of this paper are twofold. I test the synchronization hypothesis suggested by Hamermesh (2000) by creating a control group of pseudo couples, consisting of

\footnotetext{
3 Strong indications of this are that most of us prefer to sleep during the night, work in daytime, and that we prefer to have our meals at certain times, etc. Furthermore, most job contracts only allow a limited choice of working hours and temporal scope.
} 
single men and single women statistically matched together to a household unit. The assumption is that the activity timing of pseudo couples is affected in the same way by the general organization of society as the timing of real couples. However, the single man and the single woman in a pseudo couple are completely ignorant of each other's timing. The timing of pseudo couples is assumed to represent the contra factual, if couples did not synchronize activities timing within the household. By comparing the timing of matched real couples with that of matched pseudo couples, we can remove effects not caused by the proposed timing adjustment, i.e., by the organization of society in general. This is new as compared to the studies by Hamermesh (2000) and Velzen (2001).

In addition, I study how total joint leisure, i.e., the actual time that spouses meet, varies with the economic and demographic factors of the household and, to some extent, with labor market characteristics. Data for the present study are taken from the 1984 and 1993 waves of the Household Market and Nonmarket Activities (HUS). The time-use surveys contain supplementary information on the presence of other household members, e.g., the spouse, which enables us to distinguish between simultaneous time-use of spouses and when spouses actually meet. Knowing whether the spouse is involved with the respondent in an activity supplies additional information along a dimension not previously explored, e.g., issues of intra-household work burden and the cooperation of spouses. (This is also new as compared to earlier studies by Hamermesh (2000) and Velzen (2001).) I therefore distinguish between synchronized leisure and joint leisure to signify that leisure can be consumed simultaneously but not necessarily jointly.

The rest of the paper is organized as follows. Next, a theoretical model of temporal time allocation is discussed and compared to a traditional model of time allocation. Section 3 contains a presentation of the data used. To assess the effect of spouses' coordination of work timing and test the hypothesis that couples adjust the timing of activities, I perform a matching experiment with singles. Section 4 presents the results from this experiment along with empirical evidence on the timing dependence of various activities including market work. In Section 5, I investigate to what extent couples are together and how this varies 
with the economic and demographic factors of the household. Finally, Section 6 gives a summary of the paper and concludes.

\section{A temporal framework of time allocation}

Let us assume that a couple has preferences over private and joint leisure (i.e. togetherness). ${ }^{4}$ I expect the valuation of time alone and time together with the spouse to depend on the nature of and to what end various activities are performed. It is, for instance, plausible to assume that most spouses want to enjoy recreational activities together, while certain household activities are preferably done alone. However, to maintain simplicity in the theoretical framework below, I will assume that a person performs either work or leisure. In this framework, it is also assumed that if spouses consume leisure at the same time, they are together.

The allocation problem of the household is formulated as an intertemporal problem over a sequence of small indivisible time periods. The household consists of a husband $(m)$ and a wife $(f)$. Let the total time endowment (a day or a week) be $T$, which is divided into small, equally spaced and indivisible time periods denoted by $t$. Each $t=1, \ldots, T$ can, for instance, be considered as an hour. Assume that the utility function of the household can be expressed as $^{5}$

$$
U=U\left(Z_{m}\left[l_{m 1}, \ldots, l_{m T}\right], Z_{f}\left[l_{f 1}, \ldots, l_{f T}\right], Z^{J}\left[l_{1}^{J}, \ldots, l_{T}^{J}\right], x\right)
$$

where $x$ is the household's consumption of market goods, ${ }^{6} l_{s t}$ is any type of leisure, and $l_{t}^{J}$ is jointly consumed leisure, $s=m, f$. Here, $l_{s t}$ and $l_{t}^{J}$ are dichotomous variables, equalling

\footnotetext{
${ }^{4}$ This section relies heavily on Hamermesh (2000).

5 The maximand of the household is assumed to be well-behaved; real-valued, continuous and quasiconcave.

${ }^{6} x$ is the aggregate (over household members and time intervals) consumption of market goods of the household and I assume that the Hicksian composite commodity theorem holds. Hence, a well-behaved reduced-form utility function can be defined as in (1), which (subject to constraints below) yields the same solution as maximizing a utility function with individual consumption of $x$ as arguments.
} 
one if leisure of a specific type is consumed at hour $t$, and zero otherwise. ${ }^{7}$

Private and joint leisure are defined as, respectively,

$$
\begin{aligned}
l_{s t}^{P} & =\left(1-l_{u t}\right) l_{s t} ; s, u=m, f ; u \neq s, \\
l_{t}^{J} & =l_{m t} l_{f t} .
\end{aligned}
$$

Private and joint leisure are hence functions of the underlying choice variables $l_{s t}, s=m, f$, $t=1, \ldots, T$.

The utility function is maximized, subject to a budget constraint

$$
\sum_{s=m, f} \sum_{t=1}^{T}\left(1-l_{s t}\right) w_{s t}=x,
$$

where $w_{s t}$ is the exogenously given marginal net wage-rate at $t$ for spouse $s=m, f$, and the price of market goods is set to 1. Discounting is ignored. Like Hamermesh $(1999,2000)$, it is assumed that $w_{s t}$ is exogenously determined on the market and may vary over $t$, since the demand and supply conditions of labor may vary over $t$. In this model, the usual time constraint is always satisfied since $l_{s t}$ is a dichotomous variable, $s=m, f, t=1, \ldots, T$.

The maximization of (1) subject to (4) leads to the couple's optimal choice of market goods $x$ and leisure sequences $\left\{l_{s}\right\}=l_{s 1}, \ldots, l_{s T}, s=m, f$. From (2) and (3), the optimal sequences of private and joint leisure can be constructed. The total (e.g. daily) demand for leisure (of each type) is found by summing the elements in these sequences over $t$.

Spouse $s$ will work at $t$ if $w_{s t}>w_{s t}^{*}$, where $w_{s t}^{*}$ is his or her reservation wage at $t$. The reservation wage may vary over $t$ and $s$ and will be determined by the (possible mutual) preference for enjoying leisure together verses enjoying it alone, and by the preference to consume market goods.

Spouses' timing of leisure and work need not be separable. One or several arguments in $Z^{J}$ will be positive if spouses' leisure is consumed jointly, but if a couple is indifferent about consuming leisure jointly, $Z^{J}[\cdot]$ can be omitted from (1). A couple has a preference

\footnotetext{
${ }^{7}$ Following the household production literature, $Z^{J}$ may be regarded as the output from home production.
} 
for being at home simultaneously (and thus being together) if the production of $Z^{J}$ yields additional utility, i.e., if $\frac{\partial U}{\partial Z^{J}}>0$ (or, alternatively, the couple might have a preference for asynchronous leisure, i.e. $\left.\frac{\partial U}{\partial Z^{J}}<0\right)$. If this is the case, the timing of the spouses' leisure is not separable in utility since, in order to maximize utility, spouses seek coordination of work and leisure schedules.

The empirical implication of this model is that a preference for simultaneous leisure leads to interdependence between the timing of market work and leisure within the household, given the total supply of market work.

In a traditional time allocation model, it is assumed that the Hicksian composite commodity theorem holds for the aggregate over $T$ and that the utility is maximized with respect to the aggregate. Aggregation can therefore be misleading if the utility function is not weakly separable over $t$, i.e. if the timing of leisure consumption is of importance. ${ }^{8}$

\section{Data}

In this section, I describe the data used for this study. The data are taken from the Household Market and Nonmarket Activities (HUS). ${ }^{9} \quad$ The 1984 and 1993 waves of data collection included time-use surveys. For each respondent, a time-use diary was collected by telephone for two randomly selected days, normally a weekday (Mon.-Fri.) and a weekend day (Sat.Sun.). In most households with two spouses, both were interviewed concerning the same designated days. No fixed format was used either for time slots or for activities, the smallest time interval being 1 minute. The respondent's own words were recorded by the interviewer and later activity coded.

\footnotetext{
8 The traditional model may, however, be correct if Hicksian separability holds, i.e., the price vector $\mathbf{w}_{s}=\left\{w_{s 1}, \ldots, w_{s T}\right\}$ for $s=m, f$, is always proportional across households to some fixed base price vector $\mathbf{w}_{s}^{0}$, so that $\mathbf{w}_{s}=c_{s} \mathbf{w}_{s}^{0}$ for some scalar $c_{s}$. This means that, for instance, overtime payment arrangements cannot differ across households. All households must, in relation to their earnings for working at hour $a$ $(0 \leq a \leq T)$, have the same earnings for working at $t$. Whether this is a plausible assumption is seldom empirically tested, however, presumably since detailed institutional wage data that contain information on each individual's wage-rate for all $t$ rarely are available.
}

9 See Klevmarken \& Olovsson (1993) and Flood, Klevmarken \& Olovsson (1996). 
The sample used in this paper is restricted to cohabiting spouses, aged 18 or more, where both spouses reported in the main interview that they were employed. ${ }^{10}, 11$ Most respondents participated both on a weekday (Mon.-Fri.) and on a weekend day (Sat.-Sun.). However, market work is unusual on Saturdays and Sundays. Consequently, there will be little variation in data depending on market work timing during weekend days. I therefore excluded weekend day responses (i.e. Saturdays and Sundays). These restrictions give a sample of a total of 511 (516) two-earner households/time-use interviews in 1984 (1993). Only information on primary activities was used.

I classify the activities according to the following list:

- Household work (H) - Active and passive child-care, care of sick child. Preparing meals, doing the dishes, cleaning, washing, ironing and household management. Repair and maintenance of own home and vacation home, yard work. Repair and maintenance of motor vehicle, boat. Taking care of sick adult or animal. Purchases of everyday goods and clothing, consumer durables, private services and public services.

- Leisure (L) - Meals, studies, church and organizational activities, sport activities etc., TV, radio, hobbies, reading, telephone calls, conversations etc. Purchases of private and public health and medical care and dental care.

- Sleep and rest $(\mathrm{S})$ - Sleeping and resting, personal hygiene, changing clothes etc.

- Market work (N) - Gainful employment including lunch and coffee breaks, official job-related travels, applying for work and military service.

Traveling time in connection with the activity was included for all activities. The time-use data were merged with additional information from the main survey regarding the respondent's employment status and economic and demographic background.

\footnotetext{
${ }^{10}$ Households with two cohabiting adults of the same sex were excluded from the sample.

11 A person who has been on leave from work (e.g. parental leave to take care of a child) longer than 8 weeks is coded as unemployed (not in the labor force).
} 
Besides the information on the total time that each respondent spent in each of these activities during a day, I defined a set of dummy variables (one for each type of activity $H, L, S$, and $N$ ), where the day is divided into $T=60 \times 24=1440$ minutes;

$$
l_{s t}^{k}=\left\{\begin{array}{l}
1 \text { if spouse } s=m, f \text { performed activity } k=H, L, S, N \\
\text { during minute } t \\
0 \text { else. }
\end{array}\right.
$$

\subsection{Sample characteristics of the temporal pattern of time-use}

The top row of Figure 1 provides a cross gender and year comparison of the fraction of workers engaged in market work at different times of the day during Monday-Friday. Most market work is performed in daytime. A working day normally starts at 7 or 8 a.m. and lasts until 4 or 5 p.m. The fractions at work fall rapidly for both men and women after 4 p.m., and during evenings and nights only few people work in the market. A larger fraction of men as compared to women are at work at any hour of the day, which is what should be expected since, on average, men have longer working days and work full-time to a larger extent than women. There are more women at work in the 1990s as compared to the 1980s, which is expected considering the rise in female working hours in this period.

A decomposition into the different nonmarket activities is shown in the bottom row of Figure 1 and in Figure 2. The pattern is as could be expected. Leisure and household work activities increase at around 6 a.m., which is right before most people go to work. There is also a temporary peak of leisure and household work at noon. At 4 p.m., men and women increasingly engage in leisure activities. This increase continues until 9.30 p.m. Thereafter, at 10 p.m. or so, sleep becomes the dominating activity. The fractions of men and women doing some sort of household work also increase at 4 p.m., i.e., the hour after which most people arrive home from work, but falls again in the evening hours. On average, men and women go to bed at around 10 p.m. and sleep until 6 a.m. or 7 a.m. We can note a small increase in the fraction that sleeps or rests at around 5 p.m.

Not unexpectedly, we can detect some marked differences in the temporal time-use be- 

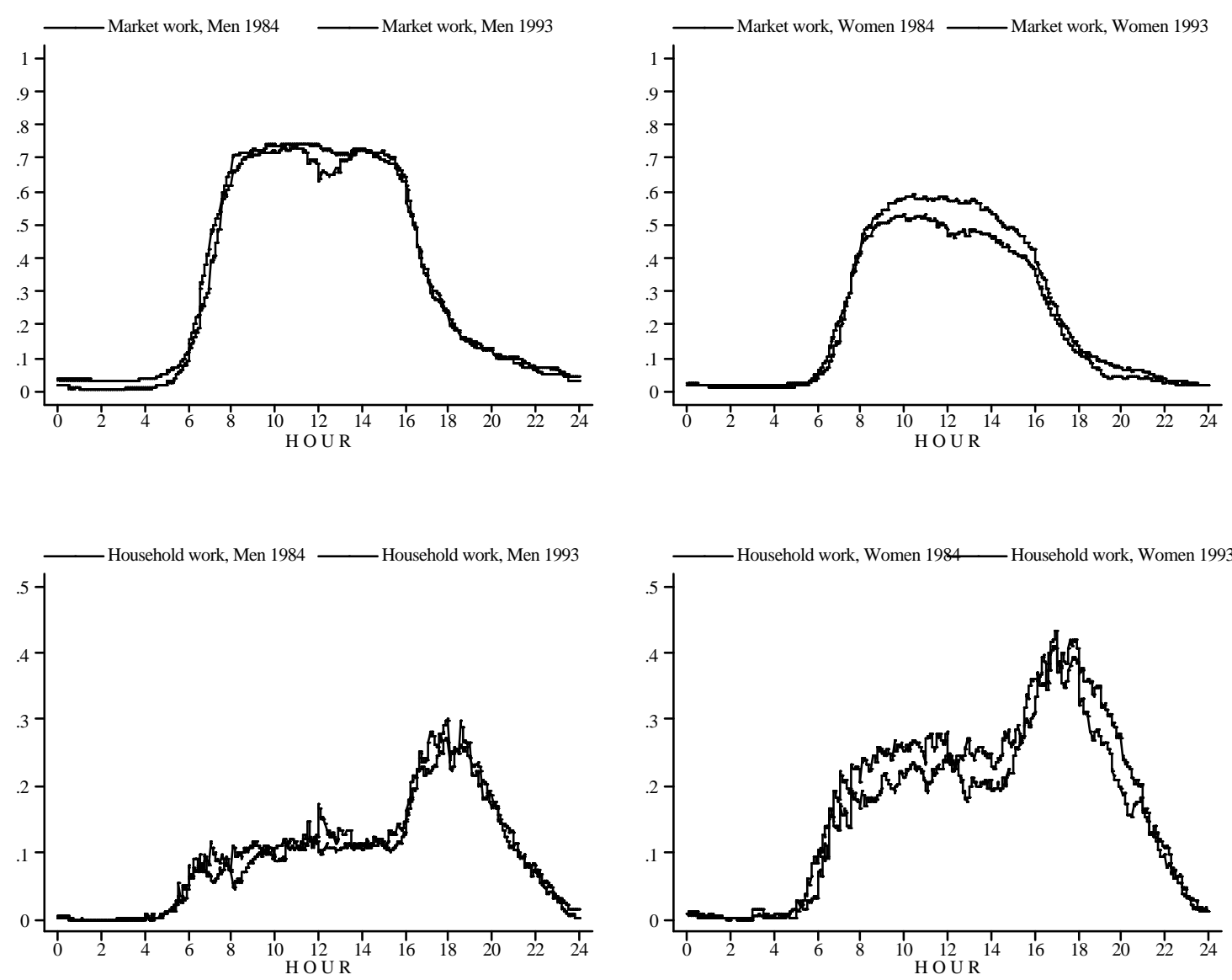

Figure 1: Fractions in market work (top row) and household work including child care (bottom row), by hour after midnight, men (right) and women (left), two-earner households, Mon.-Fri. 

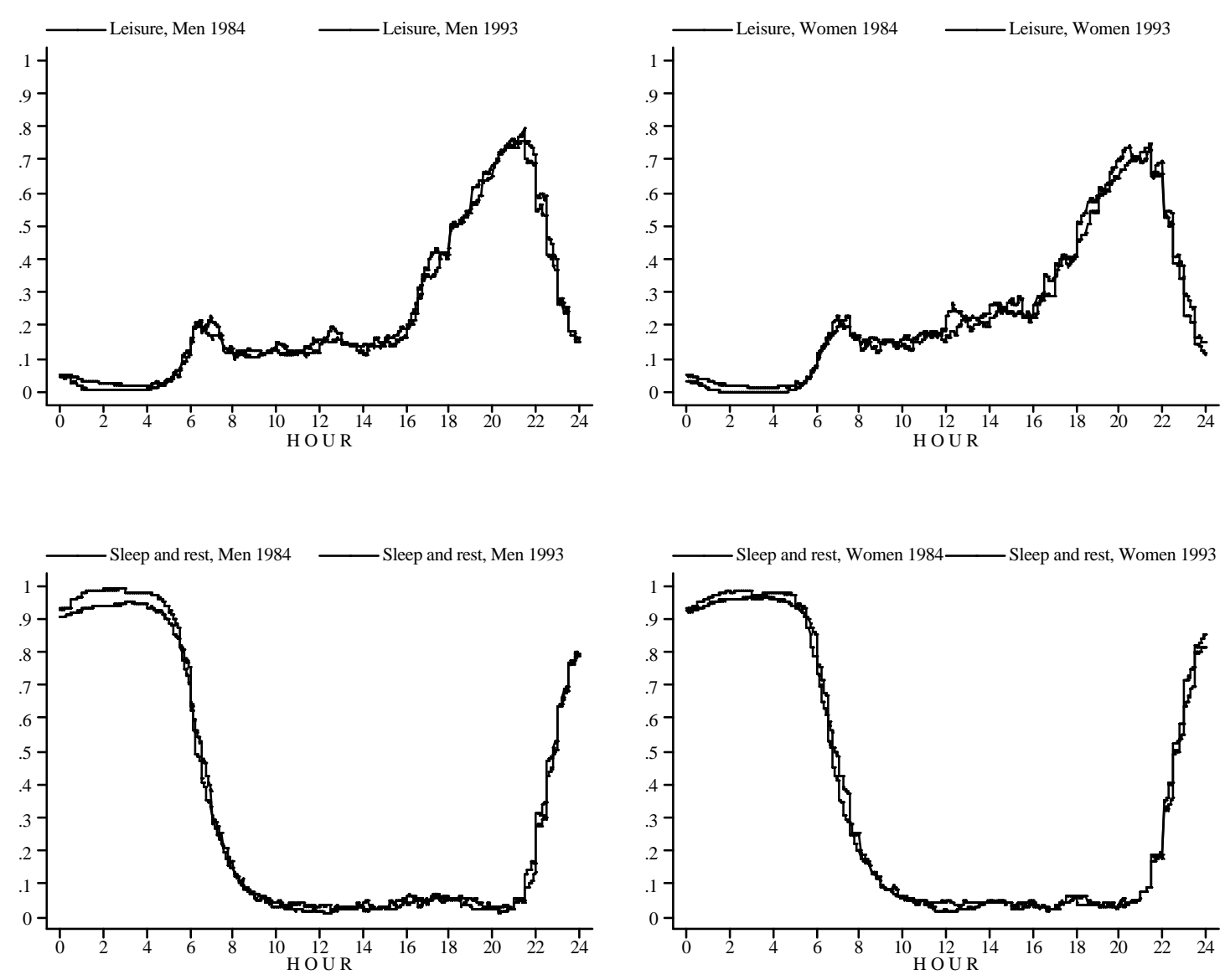

Figure 2: Fractions in leisure (top row) and sleep and rest (bottom row), by hour after midnight, men (right) and women (left), two-earner households, Mon.-Fri. 
tween men and women. A larger fraction of women engage in household work activities as compared to men, both in the evening of a typical working day and in daytime. This, and the fact that women perform more leisure in daytime, once more indicates that woman more often than men work part of the day and part of the week. In the evenings, women engage in leisure at about the same frequency as men but engage more than men in household work. Even though the activity definition used is quite broad, one possible interpretation is that the time-use of women is more fragmentary as compared to that of men.

The fraction of women working in the market is, as we noted earlier, lower as compared to men at all hours. However, on average, women seem to work at about the same hours as men, i.e. between 7 a.m. and 4 p.m. The fraction carrying out market work falls less dramatically and somewhat earlier in the afternoon for women, which is an impact of women's shorter working days, although they start at about the same hour in the morning. This pattern is about the same for women in both 1984 and 1993.

There are also some differences across years for women. As compared to the 1980s, we see that the higher frequency of market work in the 1990s is combined with less household work, both in the evenings and in daytime (i.e., when market work is frequently performed).

\section{Testing for intra-household timing adjustment}

In this section, we will test the timing adjustment hypothesis suggested by Hamermesh (2000) by creating a control group of pseudo couples, consisting of single men and single women matched together to a household unit. Pseudo couples are obtained by statistically matching single men and single women into pseudo households similar to observed twoearner households, the behavior of which can be compared to that of true couples (details about the matching can be found in Appendix). The assumption is that the activity timing of pseudo couples is affected by the general organization of society in the same way as the timing of real couples. However, the single man and the single woman in a pseudo couple are completely ignorant of the each other's timing. Hence, by comparing the timing of real couples with that of matched pseudo couples, we should be able to remove effects that are 
not caused by the proposed timing adjustment, i.e., the effect of the general organization of society.

The hypothesis is the following. If couples adjust their working schedules in order to enjoy more synchronous leisure, this should appear in the data by a higher correlation in the timing and more simultaneous leisure and household work among matched true couples than among matched pseudo couples, given the total supply of market work.

The aim of the matching is to generate two matched samples in addition to the original sample of couples:

1. A control group of pseudo couples, consisting of single males and single females matched together to a household unit.

2. The treatment group of true couples, which is defined by matches to pseudo couples.

To generate the desired treatment group and control group, I employ a non-standard way of matching. Usually when statistical matching is done, a treated unit belonging to a relatively small pool of treated is statistically matched on the basis of a set of observable covariates (matching variables) with a control unit belonging to a relatively large pool of nontreated. The present situation is different in two ways. First, to compare couples that adjust their timing with couples that do not (pseudo couples), we need to generate a set of pseudo couples out of singles. Second, since the sample size of singles (of each gender) is about one fifth as compared to that of couples, the strategy is to match couples to singles, i.e. a control unit is matched to a treated unit. The traditional approach is to do the opposite. In 1984, there were 103 (109) single males (single females) who reported in the main interview that they were employed and for whom we have a weekday (Mon.-Fri.) response. In 1993, the corresponding sample sizes were 170 (163) single males (single females). ${ }^{12}$

The matching algorithm employed here simultaneously matches a single male to a single woman with a pseudo couple and this pseudo couple to a real couple ("double matching").

\footnotetext{
12 The sample of singles is taken from the same database as the original sample of couples presented so far.
} 
The matching criterion is based upon the nearest available pair matching, using the Mahalanobis metric to define distance with respect to a set of matching variables. The matching algorithm follows Rubin (1979). (Details can be found in the Appendix.) Matching was made without replacement and separately for each year, which resulted in 103 (163) couples in 1984 (1993) in the control group and the treatment group, respectively.

It is important to consider how matching is done, since singles and individuals living as a couple differ in many ways. By comparing the outcomes for the treatment group with those in the control group, I hold constant for the matching variables used. It is of particular interest that the treated and non-treated work about the same amount of hours in the market since we compare the timing dependence and the degree of synchronization. I therefore include total hours of market work on the day of the interview (MW) among the matching variables. Households (which are included in the matching) may therefore vary in their choices of timing of work over the day, but not in the total hours worked. Studies by Hamermesh (2000) and Velzen (2001) found that the presence of fairly young children had a negative impact on the degree of synchronization of work and leisure schedules. To avoid that outcomes depend on age and family structure, I included the age of the respondent and the number of children in the household in age brackets 0-2, 3-6, 7-12 and 13-18 among the matching variables. I also included the number of years of schooling. Both education and seniority (i.e. service length with the same employer) serve as proxies for the individual situation on the labor market. Seniority is partly captured by the age of the respondent, which is already included. It is possible that profession is important in explaining the individual influence over working schedules. However, due to the rather small sample size, I only include an indicator variable for self-employment.

I present summary statistics for the original sample of couples and the sample of singles in Tables 1, 2 and $3 .^{13}$ Couples are, on average, older, have more children of all ages and are self-employed to a greater extent than singles. There are also differences in the working

\footnotetext{
${ }^{13}$ I only present summary statistics for those singles that were matched (i.e. the pseudo couples), and not for all singles used in the matching procedure, since the number of single males and single females was almost equal each year.
} 
Table 1: Summary statistics, all couples

\begin{tabular}{c|cccc|cccc}
\hline \hline & \multicolumn{4}{|c|}{$1984, \mathrm{~N}=511$} & \multicolumn{4}{c}{$1993, \mathrm{~N}=516$} \\
Variable & Mean & Std. Dev. & Min & Max & Mean & Std. Dev. & Min & Max \\
\hline age $_{m}$ & 42.793 & 10.473 & 20.000 & 70.000 & 44.986 & 10.603 & 21.000 & 78.000 \\
age $_{f}$ & 40.094 & 10.244 & 18.000 & 64.000 & 42.564 & 10.582 & 20.000 & 75.000 \\
\#children 0-2 & 0.080 & 0.279 & 0.000 & 2.000 & 0.095 & 0.293 & 0.000 & 1.000 \\
\#children 3-6 & 0.241 & 0.515 & 0.000 & 3.000 & 0.205 & 0.491 & 0.000 & 2.000 \\
\#children 7-12 & 0.399 & 0.643 & 0.000 & 3.000 & 0.318 & 0.626 & 0.000 & 3.000 \\
\#children 13-18 & 0.432 & 0.671 & 0.000 & 3.000 & 0.341 & 0.620 & 0.000 & 3.000 \\
schooling & 11.170 & 3.683 & 6.000 & 30.000 & 12.068 & 3.356 & 6.000 & 25.000 \\
schooling $_{f}$ & 10.879 & 3.129 & 6.000 & 25.000 & 12.163 & 3.190 & 6.000 & 27.000 \\
self employed & 0.192 & & 0.000 & 1.000 & 0.161 & & 0.000 & 1.000 \\
self employed $_{f}$ & 0.067 & & 0.000 & 1.000 & 0.076 & & 0.000 & 1.000 \\
MW $_{m}$ & 8.108 & 4.699 & 0.000 & 24.000 & 7.894 & 4.230 & 0.000 & 18.167 \\
MW $_{f}$ & 5.080 & 4.194 & 0.000 & 15.167 & 5.699 & 4.305 & 0.000 & 18.750 \\
\hline \hline
\end{tabular}

hours depending on cohabiting status. Single women (men) work more (less) hours on the market as compared to women (men) in a couple.

A comparison of the matched samples gives some idea of how successful the matching algorithm is. Compositional differences between control and treatment groups after matching are not desirable, since they may to some extent contribute to differences in outcome. By comparing summary statistics for controls and treated, in Tables 2 and 3 for 1984 and 1993, respectively, we note that the matching algorithm has generated matched samples that are quite similar with respect to most matching variables. ${ }^{14}$ We note for instance that there is exactly the same number of self-employed in the two groups and that most other variables do not differ a great deal in the mean. Some dissimilarities between the treatment and control groups remain, however, especially for 1993. Husbands in the treatment group are older than matched single males and couples belonging to the treatment group have fewer children in the age bracket 13-18 than matched single women. Wives in the treatment group work somewhat less than matched single women, which is fairly problematic since this difference

\footnotetext{
14 Obviously, for finite sample sizes, matching variables are likely to differ between units for at least some of the matches.
} 
Table 2: Summary statistics for matched samples 1984

\begin{tabular}{|c|c|c|c|c|c|c|c|c|}
\hline \multirow{2}{*}{$\begin{array}{l}\mathrm{N}=103 \\
\text { Variable }\end{array}$} & \multicolumn{4}{|c|}{$\begin{array}{l}\text { Pseudo couples } \\
\text { (control group) }\end{array}$} & \multicolumn{4}{|c|}{$\begin{array}{l}\text { Subset of matched real couples } \\
\text { (treatment group) }\end{array}$} \\
\hline & Mean & Std.Dev & Min & Max & Mean & Std.Dev & Min & Max \\
\hline $\operatorname{age}_{m}$ & 35.408 & 13.003 & 19.000 & 74.000 & 38.689 & 11.962 & 20.000 & 70.000 \\
\hline $\operatorname{age}_{f}$ & 36.825 & 13.802 & 19.000 & 64.000 & 36.485 & 12.578 & 18.000 & 64.000 \\
\hline \#children $0-2_{m}$ & 0.000 & 0.000 & 0.000 & 0.000 & & & & \\
\hline \#children $0-2_{f}$ & 0.000 & 0.000 & 0.000 & 0.000 & & & & \\
\hline \#children 0-2 & & & & & 0.000 & 0.000 & 0.000 & 0.000 \\
\hline \#children $3-6_{m}$ & 0.039 & 0.277 & 0.000 & 2.000 & & & & \\
\hline \# children $3-6_{f}$ & 0.049 & 0.216 & 0.000 & 1.000 & & & & \\
\hline \#children 3-6 & & & & & 0.049 & 0.216 & 0.000 & 1.000 \\
\hline \#children $7-12_{m}$ & 0.097 & 0.329 & 0.000 & 2.000 & & & & \\
\hline \#children $7-12_{f}$ & 0.136 & 0.397 & 0.000 & 2.000 & & & & \\
\hline \#children 7-12 & & & & & 0.117 & 0.351 & 0.000 & 2.000 \\
\hline \# children $13-18_{m}$ & 0.165 & 0.487 & 0.000 & 3.000 & & & & \\
\hline \#children $13-18_{f}$ & 0.243 & 0.494 & 0.000 & 2.000 & & & & \\
\hline \#children 13-18 & & & & & 0.155 & 0.414 & 0.000 & 2.000 \\
\hline schooling $_{m}$ & 10.806 & 3.042 & 6.000 & 25.000 & 11.058 & 2.967 & 6.000 & 20.000 \\
\hline $\operatorname{schooling}_{f}$ & 11.136 & 2.914 & 6.000 & 20.000 & 11.233 & 2.773 & 6.000 & 20.000 \\
\hline self employed ${ }_{m}$ & 0.146 & & 0.000 & 1.000 & 0.146 & & 0.000 & 1.000 \\
\hline self employed ${ }_{f}$ & 0.049 & & 0.000 & 1.000 & 0.049 & & 0.000 & 1.000 \\
\hline $\mathrm{MW}_{m}$ & 7.541 & 4.953 & 0.000 & 24.000 & 7.619 & 4.931 & 0.000 & 19.083 \\
\hline $\mathrm{MW}_{f}$ & 6.363 & 3.997 & 0.000 & 13.917 & 6.077 & 4.106 & 0.000 & 12.250 \\
\hline
\end{tabular}


Table 3: Summary statistics for matched samples 1993

\begin{tabular}{|c|c|c|c|c|c|c|c|c|}
\hline \multirow{2}{*}{$\begin{array}{l}\mathrm{N}=163 \\
\text { Variable }\end{array}$} & \multicolumn{4}{|c|}{$\begin{array}{l}\text { Pseudo couples } \\
\text { (control group) }\end{array}$} & \multicolumn{4}{|c|}{$\begin{array}{l}\text { Subset of matched real couples } \\
\text { (treatment group) }\end{array}$} \\
\hline & Mean & Std.Dev & Min & Max & Mean & Std.Dev & Min & Max \\
\hline $\operatorname{age}_{m}$ & 37.258 & 12.763 & 19.000 & 64.000 & 41.607 & 11.475 & 21.000 & 76.000 \\
\hline $\operatorname{age}_{f}$ & 39.405 & 14.368 & 19.000 & 89.000 & 39.926 & 12.227 & 20.000 & 75.000 \\
\hline \#children $0-2_{m}$ & 0.018 & 0.135 & 0.000 & 1.000 & & & & \\
\hline \# children $0-2_{f}$ & 0.018 & 0.135 & 0.000 & 1.000 & & & & \\
\hline \#children 0-2 & & & & & 0.012 & 0.110 & 0.000 & 1.000 \\
\hline \#children $3-6_{m}$ & 0.025 & 0.155 & 0.000 & 1.000 & & & & \\
\hline \#children $3-6_{f}$ & 0.067 & 0.252 & 0.000 & 1.000 & & & & \\
\hline \#children 3-6 & & & & & 0.049 & 0.217 & 0.000 & 1.000 \\
\hline \#children $7-12_{m}$ & 0.055 & 0.278 & 0.000 & 2.000 & & & & \\
\hline \#children $7-12_{f}$ & 0.129 & 0.418 & 0.000 & 2.000 & & & & \\
\hline \#children 7-12 & & & & & 0.080 & 0.314 & 0.000 & 2.000 \\
\hline \# children $13-18_{m}$ & 0.147 & 0.434 & 0.000 & 3.000 & & & & \\
\hline \#children $13-18_{f}$ & 0.276 & 0.601 & 0.000 & 3.000 & & & & \\
\hline \#children 13-18 & & & & & 0.190 & 0.479 & 0.000 & 2.000 \\
\hline schooling $_{m}$ & 11.982 & 2.918 & 7.000 & 22.000 & 11.736 & 2.629 & 7.000 & 20.000 \\
\hline $\operatorname{schooling}_{f}$ & 12.147 & 3.009 & 5.000 & 20.000 & 11.951 & 2.733 & 6.000 & 20.000 \\
\hline self employed $_{m}$ & 0.141 & & 0.000 & 1.000 & 0.141 & & 0.000 & 1.000 \\
\hline self employed ${ }_{f}$ & 0.031 & & 0.000 & 1.000 & 0.031 & & 0.000 & 1.000 \\
\hline $\mathrm{MW}_{m}$ & 6.535 & 4.926 & 0.000 & 17.333 & 6.792 & 4.672 & 0.000 & 16.450 \\
\hline $\mathrm{MW}_{f}$ & 6.149 & 4.246 & 0.000 & 14.750 & 5.607 & 4.313 & 0.000 & 12.500 \\
\hline
\end{tabular}


may very well result in more synchronous leisure among the treated.

Next, in Section 4.1, I will examine the timing dependence between spouses and make comparisons across the three samples. In Section 4.2, I will study the outcome in synchronous leisure and household work for the groups of treated and nontreated.

\subsection{Independence test}

The choices of the husband and the wife whether to perform activity $k$ during $t$ result in a $2 \times 2$ outcome table,

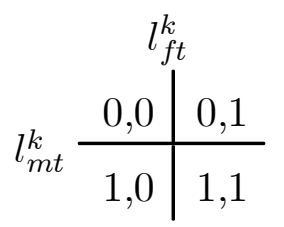

where the upper left cell represents a household where neither of the spouses was active, the upper right cell represents a household where the wife was active but the husband was not, etc. If $l_{m t}^{k}$ and $l_{f t}^{k}$ are independent, so is the timing of the spouses. This is tested using Pearson's $\chi^{2}$-test of independence. The test is performed separately for the original sample of all couples, the subset of matched couples (the treatment group) and the sample of pseudo couples (the control group), by hour, activity, and year.

The original indicator variables were defined for each minute (see Section 3). Instead of testing independence for each of the 1440 minutes in a day, I have chosen to aggregate the original indicator variables to hours and test for independence for each of the 24 hours. For a specific hour and activity, the hourly dummy variable is coded as 1 if the activity was performed within that hour, and 0 if not. This coding has its drawbacks, since it disregards both the duration and the placement of a particular activity within a specific hour. In some cases, we might hence incorrectly think that a husband and a wife were active simultaneously when, in fact, they were not. ${ }^{15}$

\footnotetext{
15 This would happen if, for instance, one spouse performed a specific activity during the first 30 minutes of the hour and the other spouse during the second 30 minutes of the same hour. The definition of these hourly dummies is not exclusive, since a respondent can be recorded as doing more than one activity during the same hour.
} 
To save space, I will only present the estimated $p$-value of each test. As for the sample of all couples, the results indicate that the dependence in instantaneous timing between spouses is significant and positive for most hours and most activities, see Table 4 . We note that independence in market work timing cannot be rejected during nights and evenings. This may be a result of too little variation at those hours. However, during the time when most market work is performed (between 6 a.m. and 3 p.m.), the results suggest that instantaneous timing in market work is strongly dependent. Whether one of the spouses performs market work at $t$ provides information about whether the other spouse is doing it too. Spouses organize the timing of leisure activities such that they are enjoyed at the same time. The null of independence is rejected at the 5 percent level for all hours in 1984 and most hours in 1993. Timing dependence is less frequent in household work and sleep as compared to leisure. For 1984, independent timing of household work is rejected during afternoons and evenings, but not in the mornings. The timing of sleep is independent in the afternoon but not otherwise. The results are similar for 1993.

The corresponding tests of independence are shown in Table 5 for the treatment group (the subset of matched couples). In 1993, the patterns of dependence for the various activities are similar to those of the full sample of couples. The timing of market work is not made independently of spouses for the greater part of the hours when work usually is performed. In 1984, however, we cannot reject the hypothesis that timing of market work is independent during the same hours.

The main result is, however, that the instantaneous timing is frequently independent for the nontreated (i.e. the pseudo couples), as shown in Table 6. Occasionally, the null can also be rejected for pseudo couples, but those instances are few and occur at unusual hours. This result is quite interesting since individuals in both groups are very similar in many ways, including their hours of market work on the day of the interview. We hence find that real couples coordinate their activities to a major extent, while singles assigned into pseudo households do not. In leisure, and to some extent in household work, the conclusion is that one spouse's timing is of great importance for that of the other. 
Table 4: P-values from Pearson's test of independence in spouses' instantaneous timing of market work $(\mathrm{N})$, household work $(\mathrm{H})$, leisure $(\mathrm{L})$, and sleep $(\mathrm{S})$. (All two-earner households, Mo.-Fri.)

\begin{tabular}{|c|c|c|c|c|c|c|c|c|}
\hline \multirow[b]{2}{*}{$\begin{array}{c}\text { Hour after } \\
\text { midnight }\end{array}$} & \multicolumn{2}{|c|}{$\bar{N}$} & \multicolumn{2}{|c|}{$\mathrm{H}$} & \multicolumn{2}{|c|}{$\mathrm{L}$} & \multicolumn{2}{|c|}{$\mathrm{S}$} \\
\hline & 1984 & 1993 & 1984 & 1993 & 1984 & 1993 & 1984 & 1993 \\
\hline 0 & $0.542^{-}$ & $0.097^{+}$ & $0.929^{-}$ & $0.878^{-}$ & $0.000^{+}$ & $0.291^{+}$ & $0.000^{+}$ & $0.446^{-}$ \\
\hline 1 & $0.542^{-}$ & $0.801^{-}$ & $\mathrm{i}$ & $\mathrm{i}$ & $0.000^{+}$ & $0.843^{-}$ & $0.000^{+}$ & $0.738^{-}$ \\
\hline 2 & $0.574^{-}$ & $0.839^{-}$ & $1.000^{-}$ & $\mathrm{i}$ & $0.000^{+}$ & $\mathrm{i}$ & $0.000^{+}$ & $0.792^{-}$ \\
\hline 3 & $0.552^{-}$ & $0.778^{-}$ & $\mathrm{i}$ & $1.000^{-}$ & $0.000^{+}$ & $\mathrm{i}$ & $0.000^{+}$ & $0.000^{+}$ \\
\hline 4 & $0.750^{+}$ & $0.613^{-}$ & $0.000^{+}$ & $0.729^{-}$ & $0.000^{+}$ & $0.000^{+}$ & $0.000^{+}$ & $0.689^{-}$ \\
\hline 5 & $0.027^{+}$ & $0.067^{+}$ & $0.092^{+}$ & $0.000^{+}$ & $0.000^{+}$ & $0.000^{+}$ & $0.000^{+}$ & $0.120^{+}$ \\
\hline 6 & $0.011^{+}$ & $0.000^{+}$ & $0.731^{+}$ & $0.819^{+}$ & $0.000^{+}$ & $0.000^{+}$ & $0.000^{+}$ & $0.000^{+}$ \\
\hline 7 & $0.079^{+}$ & $0.001^{+}$ & $0.231^{-}$ & $0.162^{+}$ & $0.000^{+}$ & $0.000^{+}$ & $0.000^{+}$ & $0.004^{+}$ \\
\hline 8 & $0.119^{+}$ & $0.000^{+}$ & $0.120^{+}$ & $0.750^{-}$ & $0.000^{+}$ & $0.453^{+}$ & $0.021^{+}$ & $0.003^{+}$ \\
\hline 9 & $0.004^{+}$ & $0.000^{+}$ & $0.446^{+}$ & $0.040^{+}$ & $0.001^{+}$ & $0.001^{+}$ & $0.027^{+}$ & $0.035^{+}$ \\
\hline 10 & $0.006^{+}$ & $0.000^{+}$ & $0.072^{+}$ & $0.027^{+}$ & $0.000^{+}$ & $0.000^{+}$ & $0.059^{+}$ & $0.102^{-}$ \\
\hline 11 & $0.005^{+}$ & $0.000^{+}$ & $0.490^{+}$ & $0.003^{+}$ & $0.000^{+}$ & $0.103^{+}$ & $0.004^{+}$ & $0.806^{-}$ \\
\hline 12 & $0.120^{+}$ & $0.000^{+}$ & $0.031^{+}$ & $0.021^{+}$ & $0.000^{+}$ & $0.012^{+}$ & $0.024^{+}$ & $0.380^{+}$ \\
\hline 13 & $0.003^{+}$ & $0.001^{+}$ & $0.000^{+}$ & $0.016^{+}$ & $0.000^{+}$ & $0.061^{+}$ & $0.613^{-}$ & $0.000^{+}$ \\
\hline 14 & $0.000^{+}$ & $0.001^{+}$ & $0.004^{+}$ & $0.010^{+}$ & $0.000^{+}$ & $0.005^{+}$ & $0.188^{+}$ & $0.579^{+}$ \\
\hline 15 & $0.001^{+}$ & $0.001^{+}$ & $0.031^{+}$ & $0.673^{-}$ & $0.000^{+}$ & $0.001^{+}$ & $0.236^{+}$ & $0.100^{+}$ \\
\hline 16 & $0.001^{+}$ & $0.143^{+}$ & $0.077^{+}$ & $0.301^{+}$ & $0.000^{+}$ & $0.000^{+}$ & $0.840^{-}$ & $0.096^{+}$ \\
\hline 17 & $0.000^{+}$ & $0.105^{+}$ & $0.057^{+}$ & $0.059^{+}$ & $0.000^{+}$ & $0.021^{+}$ & $0.704^{+}$ & $0.109^{+}$ \\
\hline 18 & $0.013^{+}$ & $0.017^{+}$ & $0.001^{+}$ & $0.000^{+}$ & $0.000^{+}$ & $0.086^{+}$ & $0.000^{+}$ & $0.004^{+}$ \\
\hline 19 & $0.565^{+}$ & $0.094^{+}$ & $0.000^{+}$ & $0.028^{+}$ & $0.000^{+}$ & $0.003^{+}$ & $0.052^{+}$ & $0.150^{+}$ \\
\hline 20 & $0.743^{-}$ & $0.067^{+}$ & $0.000^{+}$ & $0.011^{+}$ & $0.008^{+}$ & $0.118^{+}$ & $0.457^{+}$ & $0.061^{+}$ \\
\hline 21 & $0.085^{-}$ & $0.157^{+}$ & $0.000^{+}$ & $0.002^{+}$ & $0.016^{+}$ & $0.004^{+}$ & $0.000^{+}$ & $0.000^{+}$ \\
\hline 22 & $0.741^{-}$ & $0.001^{+}$ & $0.000^{+}$ & $0.000^{+}$ & $0.000^{+}$ & $0.000^{+}$ & $0.000^{+}$ & $0.000^{+}$ \\
\hline 23 & $0.335^{-}$ & $0.138^{+}$ & $0.000^{+}$ & $0.000^{+}$ & $0.000^{+}$ & $0.000^{+}$ & $0.000^{+}$ & $0.000^{+}$ \\
\hline
\end{tabular}

Notes: i) Insufficient or no variation in data. The number of observations is 511 for 1984 and 516 for $1993 .^{+} /^{-}$indicates the sign of the dependence as measured by gamma (see Goodman and Kruskal, 1954, and StataCorp., 1999). 
Table 5: P-values from Pearson's test of independence in spouses' instantaneous timing, the treatment group

\begin{tabular}{|c|c|c|c|c|c|c|c|c|}
\hline \multirow[b]{2}{*}{$\begin{array}{c}\text { Hour after } \\
\text { midnight }\end{array}$} & \multicolumn{2}{|c|}{$\mathrm{N}$} & \multicolumn{2}{|c|}{$\overline{\mathrm{H}}$} & \multicolumn{2}{|c|}{$\mathrm{L}$} & \multicolumn{2}{|c|}{$\mathrm{S}$} \\
\hline & 1984 & 1993 & 1984 & 1993 & 1984 & 1993 & 1984 & 1993 \\
\hline 0 & $\overline{\mathrm{i}}$ & $0.811^{-}$ & $\overline{\mathrm{i}}$ & $0.911^{-}$ & $0.000^{+}$ & $0.763^{-}$ & $0.000^{+}$ & $0.756^{-}$ \\
\hline 1 & $\mathrm{i}$ & $0.911^{-}$ & $\mathrm{i}$ & $\mathrm{i}$ & $0.000^{+}$ & $0.891^{-}$ & $0.000^{+}$ & $0.891^{-}$ \\
\hline 2 & $\mathrm{i}$ & $0.937^{-}$ & $\mathrm{i}$ & $\mathrm{i}$ & $0.000^{+}$ & $\mathrm{i}$ & $0.007^{+}$ & $0.911^{-}$ \\
\hline 3 & $\mathrm{i}$ & $0.911^{-}$ & $\mathrm{i}$ & $0.000^{-}$ & $0.000^{+}$ & $\mathrm{i}$ & $0.007^{+}$ & $0.000^{+}$ \\
\hline 4 & $0.820^{-}$ & $0.800^{-}$ & $0.000^{+}$ & $0.821^{+}$ & $0.007^{+}$ & $0.000^{+}$ & $0.014^{+}$ & $0.821^{-}$ \\
\hline 5 & $0.528^{-}$ & $0.409^{-}$ & $0.055^{+}$ & $0.255^{+}$ & $0.000^{+}$ & $0.030^{+}$ & $0.126^{+}$ & $0.012^{+}$ \\
\hline 6 & $0.280^{+}$ & $0.018^{+}$ & $0.755^{+}$ & $0.164^{+}$ & $0.008^{+}$ & $0.002^{+}$ & $0.063^{+}$ & $0.058^{+}$ \\
\hline 7 & $0.256^{+}$ & $0.017^{+}$ & $0.383^{-}$ & $0.141^{+}$ & $0.005^{+}$ & $0.020^{+}$ & $0.188^{+}$ & $0.132^{+}$ \\
\hline 8 & $0.527^{+}$ & $0.004^{+}$ & $0.611^{+}$ & $0.640^{+}$ & $0.041^{+}$ & $0.599^{+}$ & $0.177^{+}$ & $0.051^{+}$ \\
\hline 9 & $0.352^{+}$ & $0.004^{+}$ & $0.259^{-}$ & $0.058^{+}$ & $0.195^{+}$ & $0.370^{+}$ & $0.433^{+}$ & $0.002^{+}$ \\
\hline 10 & $0.275^{+}$ & $0.004^{+}$ & $0.748^{-}$ & $0.081^{+}$ & $0.028^{+}$ & $0.185^{+}$ & $0.292^{+}$ & $0.185^{-}$ \\
\hline 11 & $0.127^{+}$ & $0.002^{+}$ & $0.726^{+}$ & $0.003^{+}$ & $0.000^{+}$ & $0.045^{+}$ & $0.240^{+}$ & $0.591^{+}$ \\
\hline 12 & $0.339^{+}$ & $0.000^{+}$ & $0.244^{+}$ & $0.009^{+}$ & $0.004^{+}$ & $0.050^{+}$ & $0.018^{+}$ & $0.230^{+}$ \\
\hline 13 & $0.085^{+}$ & $0.000^{+}$ & $0.141^{+}$ & $0.192^{+}$ & $0.007^{+}$ & $0.060^{+}$ & $0.569^{-}$ & $0.000^{+}$ \\
\hline 14 & $0.136^{+}$ & $0.000^{+}$ & $0.479^{+}$ & $0.133^{+}$ & $0.034^{+}$ & $0.001^{+}$ & $0.165^{+}$ & $0.945^{+}$ \\
\hline 15 & $0.096^{+}$ & $0.000^{+}$ & $0.358^{+}$ & $0.053^{+}$ & $0.037^{+}$ & $0.001^{+}$ & $0.495^{-}$ & $0.557^{+}$ \\
\hline 16 & $0.007^{+}$ & $0.135^{+}$ & $0.151^{+}$ & $0.226^{+}$ & $0.004^{+}$ & $0.004^{+}$ & $0.317^{-}$ & $0.414^{+}$ \\
\hline 17 & $0.000^{+}$ & $0.096^{+}$ & $0.055^{+}$ & $0.123^{+}$ & $0.127^{+}$ & $0.968^{+}$ & $0.638^{+}$ & $0.310^{+}$ \\
\hline 18 & $0.133^{+}$ & $0.254^{+}$ & $0.078^{+}$ & $0.189^{+}$ & $0.013^{+}$ & $0.211^{+}$ & $0.000^{+}$ & $0.310^{+}$ \\
\hline 19 & $0.820^{-}$ & $0.638^{+}$ & $0.001^{+}$ & $0.236^{+}$ & $0.013^{+}$ & $0.255^{+}$ & $0.272^{+}$ & $0.159^{+}$ \\
\hline 20 & $0.821^{+}$ & $0.488^{+}$ & $0.534^{+}$ & $0.174^{+}$ & $0.130^{+}$ & $0.170^{+}$ & $0.475^{+}$ & $0.488^{+}$ \\
\hline 21 & $0.459^{-}$ & $0.869^{+}$ & $0.025^{+}$ & $0.000^{+}$ & $0.384^{+}$ & $0.127^{+}$ & $0.066^{+}$ & $0.000^{+}$ \\
\hline 22 & $\mathrm{i}$ & $0.624^{-}$ & $0.000^{+}$ & $0.005^{+}$ & $0.000^{+}$ & $0.000^{+}$ & $0.000^{+}$ & $0.000^{+}$ \\
\hline 23 & $\mathrm{i}$ & $0.673^{-}$ & $0.001^{+}$ & $0.060^{+}$ & $0.000^{+}$ & $0.000^{+}$ & $0.000^{+}$ & $0.000^{+}$ \\
\hline
\end{tabular}

Notes: see Table 4. The number of observations is

103 for 1984 and 163 for 1993 . 
Table 6: P-values from Pearson's test of independence in spouses' instantaneous timing, the control group

\begin{tabular}{|c|c|c|c|c|c|c|c|c|}
\hline \multirow[b]{2}{*}{$\begin{array}{l}\text { Hour after } \\
\text { midnight }\end{array}$} & \multicolumn{2}{|c|}{$\mathrm{N}$} & \multicolumn{2}{|c|}{$\mathrm{H}$} & \multicolumn{2}{|c|}{$\mathrm{L}$} & \multicolumn{2}{|c|}{$\mathrm{S}$} \\
\hline & 1984 & 1993 & 1984 & 1993 & 1984 & 1993 & 1984 & 1993 \\
\hline 0 & $0.862^{-}$ & $0.026^{+}$ & $\mathrm{i}$ & $\mathrm{i}$ & $0.479^{+}$ & $0.223^{-}$ & $0.090^{+}$ & $0.166^{-}$ \\
\hline 1 & $0.862^{-}$ & $0.719^{-}$ & $\mathrm{i}$ & $\mathrm{i}$ & $0.610^{-}$ & $0.583^{-}$ & $0.295^{+}$ & $0.435^{-}$ \\
\hline 2 & $0.862^{-}$ & $0.719^{-}$ & $\mathrm{i}$ & $0.937^{-}$ & $0.803^{-}$ & $\mathrm{i}$ & $0.026^{+}$ & $0.583^{-}$ \\
\hline 3 & $0.000^{+}$ & $0.719^{-}$ & $\mathrm{i}$ & $0.937^{-}$ & $0.774^{-}$ & $0.891^{-}$ & $0.007^{+}$ & $0.668^{-}$ \\
\hline 4 & $0.000^{+}$ & $0.022^{+}$ & $0.803^{-}$ & $0.756^{-}$ & $0.662^{-}$ & $0.692^{-}$ & $0.000^{+}$ & $0.645^{-}$ \\
\hline 5 & $0.273^{+}$ & $0.807^{+}$ & $0.734^{-}$ & $0.970^{+}$ & $0.840^{-}$ & $0.152^{+}$ & $0.022^{+}$ & $0.028^{+}$ \\
\hline 6 & $0.279^{+}$ & $0.296^{+}$ & $0.746^{+}$ & $0.489^{+}$ & $0.914^{-}$ & $0.401^{+}$ & $0.134^{+}$ & $0.008^{+}$ \\
\hline 7 & $0.239^{+}$ & $0.482^{+}$ & $0.131^{+}$ & $0.904^{+}$ & $0.248^{+}$ & $0.291^{-}$ & $0.508^{+}$ & $0.808^{+}$ \\
\hline 8 & $0.646^{+}$ & $0.241^{+}$ & $0.154^{-}$ & $0.831^{-}$ & $0.287^{+}$ & $0.435^{+}$ & $0.639^{+}$ & $0.520^{-}$ \\
\hline 9 & $0.159^{+}$ & $0.109^{+}$ & $0.672^{-}$ & $0.146^{+}$ & $0.075^{+}$ & $0.615^{+}$ & $0.177^{-}$ & $0.820^{+}$ \\
\hline 10 & $0.754^{+}$ & $0.082^{+}$ & $0.589^{+}$ & $0.217^{-}$ & $0.075^{+}$ & $0.697^{+}$ & $0.749^{+}$ & $0.977^{-}$ \\
\hline 11 & $0.271^{+}$ & $0.252^{+}$ & $0.214^{+}$ & $0.867^{+}$ & $0.607^{+}$ & $0.628^{+}$ & $0.610^{-}$ & $0.300^{+}$ \\
\hline 12 & $0.082^{+}$ & $0.282^{+}$ & $0.919^{-}$ & $0.951^{-}$ & $0.519^{+}$ & $0.320^{+}$ & $0.569^{-}$ & $0.517^{-}$ \\
\hline 13 & $0.355^{+}$ & $0.107^{+}$ & $0.711^{-}$ & $0.213^{+}$ & $0.154^{+}$ & $0.177^{+}$ & $0.229^{+}$ & $0.542^{+}$ \\
\hline 14 & $0.583^{+}$ & $0.672^{+}$ & $0.475^{+}$ & $0.651^{-}$ & $0.542^{+}$ & $0.866^{+}$ & $0.361^{+}$ & $0.844^{+}$ \\
\hline 15 & $0.185^{+}$ & $0.387^{+}$ & $0.868^{+}$ & $0.905^{-}$ & $0.016^{+}$ & $0.080^{+}$ & $0.343^{-}$ & $0.502^{-}$ \\
\hline 16 & $0.754^{-}$ & $0.830^{+}$ & $0.588^{+}$ & $0.521^{+}$ & $0.828^{+}$ & $0.496^{+}$ & $0.937^{-}$ & $0.826^{+}$ \\
\hline 17 & $0.425^{+}$ & $0.943^{+}$ & $0.978^{-}$ & $0.473^{+}$ & $0.568^{-}$ & $0.685^{+}$ & $0.645^{+}$ & $0.269^{-}$ \\
\hline 18 & $0.945^{+}$ & $0.854^{-}$ & $0.664^{-}$ & $0.136^{+}$ & $0.321^{-}$ & $0.100^{-}$ & $0.638^{+}$ & $0.261^{+}$ \\
\hline 19 & $0.175^{-}$ & $0.318^{+}$ & $0.987^{-}$ & $0.354^{+}$ & $0.760^{-}$ & $0.315^{+}$ & $0.393^{-}$ & $0.574^{+}$ \\
\hline 20 & $0.277^{-}$ & $0.587^{-}$ & $0.139^{+}$ & $0.195^{+}$ & $0.171^{-}$ & $0.961^{-}$ & $0.991^{+}$ & $0.189^{-}$ \\
\hline 21 & $0.478^{-}$ & $0.309^{-}$ & $0.265^{-}$ & $0.096^{+}$ & $0.111^{+}$ & $0.886^{-}$ & $0.927^{+}$ & $0.256^{-}$ \\
\hline 22 & $0.662^{-}$ & $0.839^{+}$ & $0.343^{-}$ & $0.200^{-}$ & $0.322^{-}$ & $0.609^{+}$ & $0.266^{-}$ & $0.490^{+}$ \\
\hline 23 & $0.662^{-}$ & $0.586^{-}$ & $0.682^{-}$ & $0.583^{-}$ & $0.347^{+}$ & $0.736^{+}$ & $0.739^{+}$ & $0.086^{-}$ \\
\hline
\end{tabular}

Notes: see Table 4. The number of observations is

103 for 1984 and 163 for 1993. 
Table 7: P-values from Pearson's test of independence in spouses' instantaneous timing, treatment group and control group, 1984 and 1993 pooled

\begin{tabular}{|c|c|c|c|c|c|c|c|c|}
\hline \multirow{2}{*}{$\begin{array}{c}1984 \text { and } \\
1993 \text { pooled } \\
\text { Hour after } \\
\text { midnight }\end{array}$} & \multicolumn{4}{|c|}{$\begin{array}{c}\text { Treatment group } \\
\text { (subset of matched couples) }\end{array}$} & \multicolumn{4}{|c|}{$\begin{array}{l}\text { Control group } \\
\text { (pseudo couples) }\end{array}$} \\
\hline & $\mathrm{N}$ & $\mathrm{H}$ & $\mathrm{L}$ & $\mathrm{S}$ & $\mathrm{N}$ & $\mathrm{H}$ & $\mathrm{L}$ & $\mathrm{S}$ \\
\hline 0 & $0.775^{-}$ & $0.931^{-}$ & $0.000^{+}$ & $0.002^{+}$ & $0.048^{+}$ & $\overline{\mathrm{i}}$ & $0.477^{-}$ & $0.833^{-}$ \\
\hline 1 & $0.879^{-}$ & $\mathrm{i}$ & $0.000^{+}$ & $0.000^{+}$ & $0.684^{-}$ & $\mathrm{i}$ & $0.422^{-}$ & $0.967^{+}$ \\
\hline 2 & $0.890^{-}$ & $\mathrm{i}$ & $0.000^{+}$ & $0.002^{+}$ & $0.684^{-}$ & $0.951^{-}$ & $0.684^{-}$ & $0.378^{+}$ \\
\hline 3 & $0.844^{-}$ & $0.000^{+}$ & $0.000^{+}$ & $0.000^{+}$ & $0.069^{+}$ & $0.931^{-}$ & $0.755^{-}$ & $0.172^{+}$ \\
\hline 4 & $0.731^{-}$ & $0.005^{+}$ & $0.000^{+}$ & $0.035^{+}$ & $0.000^{+}$ & $0.643^{-}$ & $0.546^{-}$ & $0.009^{+}$ \\
\hline 5 & $0.295^{-}$ & $0.082^{+}$ & $0.000^{+}$ & $0.004^{+}$ & $0.485^{+}$ & $0.785^{-}$ & $0.345^{+}$ & $0.006^{+}$ \\
\hline 6 & $0.012^{+}$ & $0.204^{+}$ & $0.000^{+}$ & $0.006^{+}$ & $0.131^{+}$ & $0.487^{+}$ & $0.566^{+}$ & $0.003^{+}$ \\
\hline 7 & $0.007^{+}$ & $0.555^{+}$ & $0.000^{+}$ & $0.027^{+}$ & $0.158^{+}$ & $0.390^{+}$ & $0.878^{-}$ & $0.425^{+}$ \\
\hline 8 & $0.006^{+}$ & $0.474^{+}$ & $0.102^{+}$ & $0.013^{+}$ & $0.203^{+}$ & $0.352^{-}$ & $0.200^{+}$ & $0.805^{-}$ \\
\hline 9 & $0.004^{+}$ & $0.388^{+}$ & $0.134^{+}$ & $0.003^{+}$ & $0.026^{+}$ & $0.417^{+}$ & $0.141^{+}$ & $0.600^{-}$ \\
\hline 10 & $0.003^{+}$ & $0.218^{+}$ & $0.015^{+}$ & $0.475^{-}$ & $0.085^{+}$ & $0.545^{-}$ & $0.168^{+}$ & $0.773^{+}$ \\
\hline 11 & $0.001^{+}$ & $0.013^{+}$ & $0.000^{+}$ & $0.297^{+}$ & $0.098^{+}$ & $0.370^{+}$ & $0.481^{+}$ & $0.380^{+}$ \\
\hline 12 & $0.000^{+}$ & $0.005^{+}$ & $0.001^{+}$ & $0.010^{+}$ & $0.046^{+}$ & $0.760^{-}$ & $0.237^{+}$ & $0.475^{-}$ \\
\hline 13 & $00^{+}$ & $0.054^{+}$ & $0.002^{+}$ & & & $0.527^{+}$ & $0.053^{+}$ & $0.256^{+}$ \\
\hline 14 & $0.000^{+}$ & $0.112^{+}$ & $0.000^{+}$ & $0.464^{+}$ & $0.490^{+}$ & $0.999^{+}$ & $0.691^{+}$ & $0.589^{+}$ \\
\hline 15 & $0.000^{+}$ & $0.037^{+}$ & $0.000^{+}$ & $0.823^{+}$ & $0.140^{+}$ & $0.998^{-}$ & $0.004^{+}$ & $0.264^{-}$ \\
\hline 16 & $0.004^{+}$ & $0.070^{+}$ & $0.000^{+}$ & $0.783^{+}$ & $0.969^{+}$ & $0.315^{+}$ & $0.539^{+}$ & $0.903^{+}$ \\
\hline 17 & $0.000^{+}$ & $0.017^{+}$ & $0.329^{+}$ & $0.278^{+}$ & $0.540^{+}$ & $0.566^{+}$ & $0.971^{-}$ & $0.544^{-}$ \\
\hline 18 & $0.067^{+}$ & $0.032^{+}$ & $0.011^{+}$ & $0.005^{+}$ & $0.916^{-}$ & $0.324^{+}$ & $0.058^{-}$ & $0.244^{+}$ \\
\hline 19 & $0.842^{+}$ & $0.004^{+}$ & $0.017^{+}$ & $0.076^{+}$ & $0.887^{-}$ & $0.434^{+}$ & $0.585^{+}$ & $0.982^{-}$ \\
\hline 20 & $0.495^{+}$ & $0.150^{+}$ & $0.079^{+}$ & $0.336^{+}$ & $0.274^{-}$ & $0.054^{+}$ & $0.330^{-}$ & $0.319^{-}$ \\
\hline 21 & $0.733^{-}$ & $0.000^{+}$ & $0.101^{+}$ & $0.000^{+}$ & $0.216^{-}$ & $0.588^{+}$ & $0.432^{+}$ & $0.761^{-}$ \\
\hline 22 & $0.599^{-}$ & $0.000^{+}$ & $0.000^{+}$ & $0.000^{+}$ & $0.954^{+}$ & $0.091^{-}$ & $0.778^{-}$ & $0.881^{-}$ \\
\hline 23 & $0.639^{-}$ & $0.001^{+}$ & $0.000^{+}$ & $0.000^{+}$ & $0.484^{-}$ & $0.489^{-}$ & $0.419^{+}$ & $0.240^{-}$ \\
\hline
\end{tabular}

Notes: see Table 4. The number of observations is 266 . 
One might be concerned that the low sample sizes for the matched groups would not cause enough variation and that the conclusion is therefore predetermined. By pooling 1984 and 1993 and rerunning the tests of independence, I find, however, that I can reject independence in market work timing between 9 a.m. and 1 p.m. on the 10 percent level for pseudo couples, see Table 7. For the subset of matched couples the $p$-value is even lower during the same hours. The interpretation is hence that timing is influenced by the general organization of society since evidently, it also affects singles. Neglecting this may overstate the importance of intra-household timing dependence.

\subsection{The effect of timing adjustment on simultaneity}

In this subsection, I will examine if the adjustment of working schedules among couples has any effect on the outcome of synchronous leisure (broadly defined to include household work). We would expect the treated to have more synchronous leisure and household work than nontreated. If this is the case, we take this as supporting evidence for Hamermesh's (2000) hypothesis.

In order to perform this test, I need to assume that the observed outcome of the control units is representative for the unobserved outcome of the treated couples if they had not adjusted timing, conditional on the set of matching variables. I hence assume that real couples that were matched would behave like the control group of singles in the absence of timing adjustment. Further, I estimate the effect of timing adjustment as the group average difference (thus treating the response surfaces as parallel). ${ }^{16}$

I will aggregate simultaneous time spent in leisure and household work. Let $S$ be the amount of synchronous leisure (broadly defined to include household work) of the spouses, defined as

$$
S=\sum_{t=1}^{T} I\left[l_{m t}^{H}+l_{m t}^{L}\right] I\left[l_{f t}^{H}+l_{f t}^{L}\right]
$$

\footnotetext{
${ }^{16}$ Let $P_{0}$ be the population of control units and $P_{1}$ the population of treatment units. For the expected value of $S$ in $P_{i}$, given the matching variables $\mathbf{X}$, I write $\alpha_{i}+W_{i}(\mathbf{X})$, which often is called the response surface for $S$ in $P_{i}$. If response surfaces are parallel, i.e. $W_{0}(\mathbf{X})=W_{1}(\mathbf{X})=W(\mathbf{X})$, the expected treatment effect is simply the groupwise difference of $S$ (see Rubin, 1979).
} 
where $T=1440$ minutes per day and $I[\cdot]$ is the indicator function, equal to one if $[\cdot]>0$ and zero otherwise. This variable ignores simultaneity when one of the spouses was just sleeping or performing market work.

The finding is that the subset of matched couples enjoys more synchronous leisure than do pseudo couples, see Table 8 which shows the outcome with respect to synchronous leisure for the treated and nontreated. Thus, there seems to be support for the hypothesis that spouses time their activities within the household to obtain more synchronous leisure. The gain in synchronous leisure as a result of the timing adjustment is not very large, however. My estimates suggest that treated couples have about 5.9 hours/day of synchronous leisure (excluding sleeping, resting, and personal hygiene), while nontreated couples have about 5.2 hours/day of synchronous leisure (1984 and 1993 pooled). By adjusting working schedules and the timing of leisure and household work, couples hence experience a 12 percent increase (almost three quarters of an hour) in terms of more time when they can potentially meet during a normal working day. The effect is essentially the same for 1984 and 1993, and significantly different from zero at the 5 percent level in both years. ${ }^{17}$

It is noteworthy that pseudo couples obtain so much synchronous leisure. Figure 3 and Figure 4 show the distributions of $S$ by group. We note that matched couples (middle) have a thicker right-hand side tail than pseudo couples and more real households enjoy 6-7 hours/day of synchronous leisure than pseudo couples. These distributions hence differ in some respects, but perhaps not as much as one might expect considering that pseudo couples do not adjust timing within the household at all. Because the matched single male and single female are completely ignorant of each other's timing, the interpretation is once more that the organization of society in general have a great impact on timing. ${ }^{18}$

\footnotetext{
17 Part of the difference in synchronous leisure may result from singles performing more household work than someone living in a couple. In order to control for this in the matching, I tried an alternative set of matching variables. Here, I also included the total time spent on household work, leisure and sleep on the day of the interview among the set of matching variables besides the ones already included. The result of that matching was a somewhat lower estimated timing adjustment effect, as compared to the one presented in the text, although significantly different from zero in both years (0.60 [2.65] for 1984 and 0.39 [2.04] for 1993, with paired $t$-tests in brackets).

18 It is impossible to say how much of the effect can be extrapolated to couples in general. We can,
} 
Table 8: Estimated treatment effect of timing adjustment on synchronous leisure and household work (hours/day)

\begin{tabular}{|c|c|c|c|c|}
\hline $\begin{array}{c}\text { Treatment group } \\
\text { (Matched real couples) }\end{array}$ & $\begin{array}{c}\text { Mean } \\
\text { St.dev of mean } \\
\text { St.err of mean }\end{array}$ & $\begin{array}{l}1984 \\
5.78 \\
3.63 \\
0.36\end{array}$ & $\begin{array}{l}1993 \\
6.00 \\
3.59 \\
0.28\end{array}$ & $\begin{array}{c}\text { Pooled (a) } \\
5.91 \\
3.60 \\
0.22\end{array}$ \\
\hline $\begin{array}{c}\text { Control group } \\
\text { (Matched pseudo couples) }\end{array}$ & $\begin{array}{c}\text { Mean } \\
\text { St.dev of mean } \\
\text { St.err of mean }\end{array}$ & $\begin{array}{l}4.97 \\
2.75 \\
0.27 \\
\end{array}$ & $\begin{array}{l}5.38 \\
3.20 \\
0.25 \\
\end{array}$ & $\begin{array}{l}5.22 \\
3.03 \\
0.19 \\
\end{array}$ \\
\hline Difference, $\alpha$ & $\begin{array}{c}\text { Mean } \\
\text { St.err of mean } \\
\text { Paired } t \text {-test } \\
\end{array}$ & $\begin{array}{c}0.80 \\
0.27 \\
3.00(0.003) \\
\end{array}$ & $\begin{array}{c}0.62 \\
0.25 \\
2.44(0.016) \\
\end{array}$ & $\begin{array}{c}0.69 \\
0.19 \\
3.70(0.000) \\
\end{array}$ \\
\hline & Observations & 103 & 163 & 266 \\
\hline Blinder-Oaxaca decompo & $\begin{array}{c}\text { on: Composition } \\
\text { Alt. } 1 \\
\text { Alt. } 2\end{array}$ & $\begin{array}{c}\text { effect of } \alpha \\
40 \% \\
9 \%\end{array}$ & $\begin{array}{l}27 \% \\
31 \%\end{array}$ & $\begin{array}{l}32 \% \\
17 \%\end{array}$ \\
\hline
\end{tabular}

Note: $P$-value for two-sided paired $t$-test in parenthesis. a) Pooling is not rejected ( $p$-value for $\mathrm{H}_{0}$ : same mean over years is 0.629 for treated and 0.289 for controls). The composition effect is estimated in two ways:

Alt. 1) The difference in $\overline{\mathbf{x}}$ is weighted by the coefficient vector of real couples, $\hat{\beta}_{1}$, i.e., the composition effect is $\frac{1}{2}\left[\hat{\beta}_{1}^{\prime}\left(\overline{\mathbf{x}}_{1}-\overline{\mathbf{x}}_{m 0}\right)+\hat{\beta}_{1}^{\prime}\left(\overline{\mathbf{x}}_{1}-\overline{\mathbf{x}}_{f 0}\right)\right]$.

Alt. 2) The difference in $\overline{\mathbf{x}}$ is weighted by the coefficient vector of pseudo couples, $\hat{\beta}_{0}$, i.e., the composition effect is $\frac{1}{2}\left[\hat{\beta}_{m 0}^{\prime}\left(\overline{\mathbf{x}}_{1}-\overline{\mathbf{x}}_{m 0}\right)+\hat{\beta}_{f 0}^{\prime}\left(\overline{\mathbf{x}}_{1}-\overline{\mathbf{x}}_{f 0}\right)\right]$.

Here $\overline{\mathbf{x}}_{1}, \overline{\mathbf{x}}_{m 0}$, and $\overline{\mathbf{x}}_{f 0}$ are the mean vectors (including a constant) of the subset of matched couples, single men and single women, respectively, and $\hat{\beta}_{1}, \hat{\beta}_{m 0}$, and $\hat{\beta}_{f 0}$ are the corresponding estimated coefficient vectors from separate OLS regressions of $S$ on $\mathbf{x}$. 

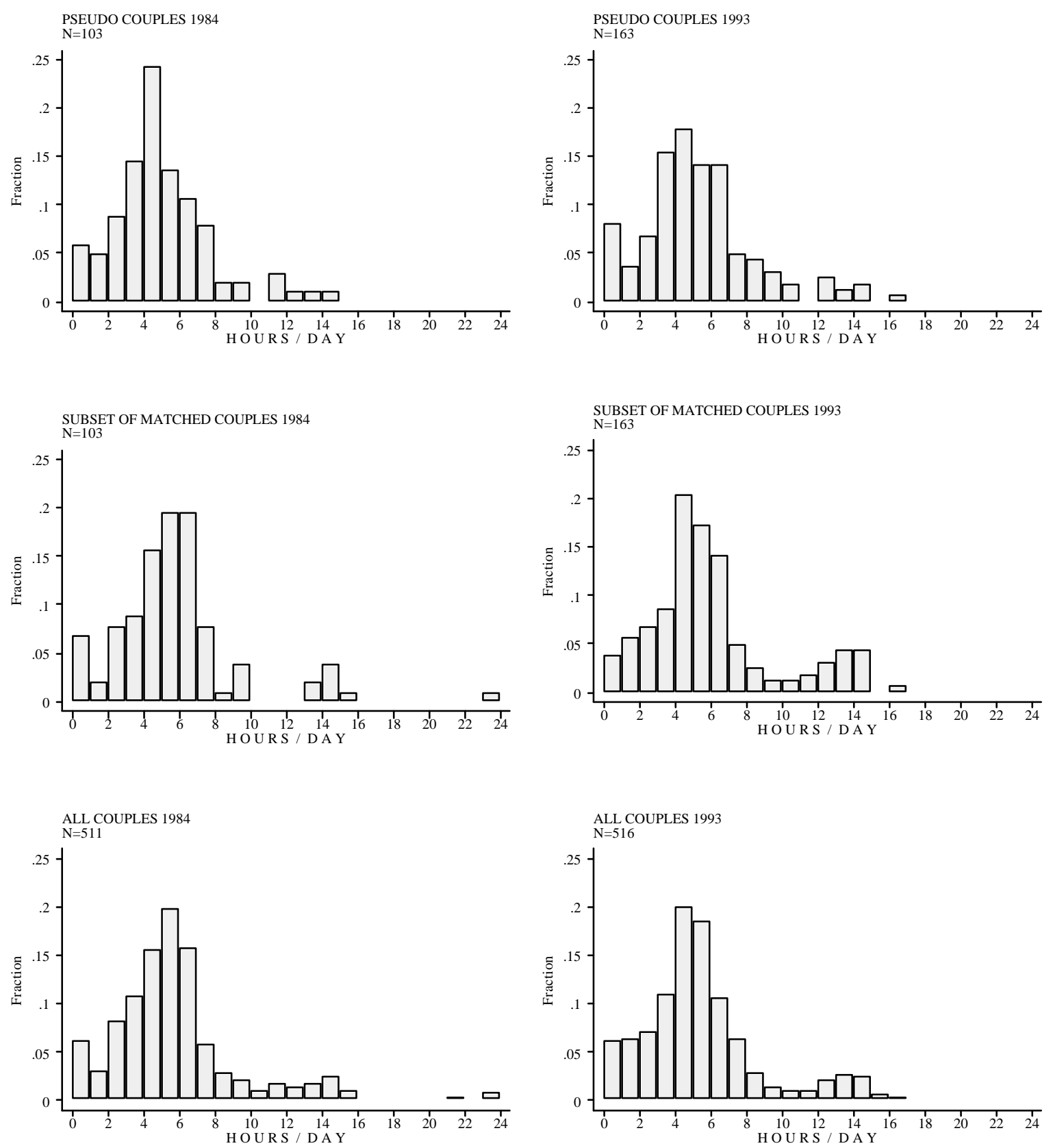

Figure 3: Hours of synchronous leisure (including household work) for pseudo couples (top row), the subset of matched couples (middle), and all couples (bottom), 1984 (left) and 1993 (right). 

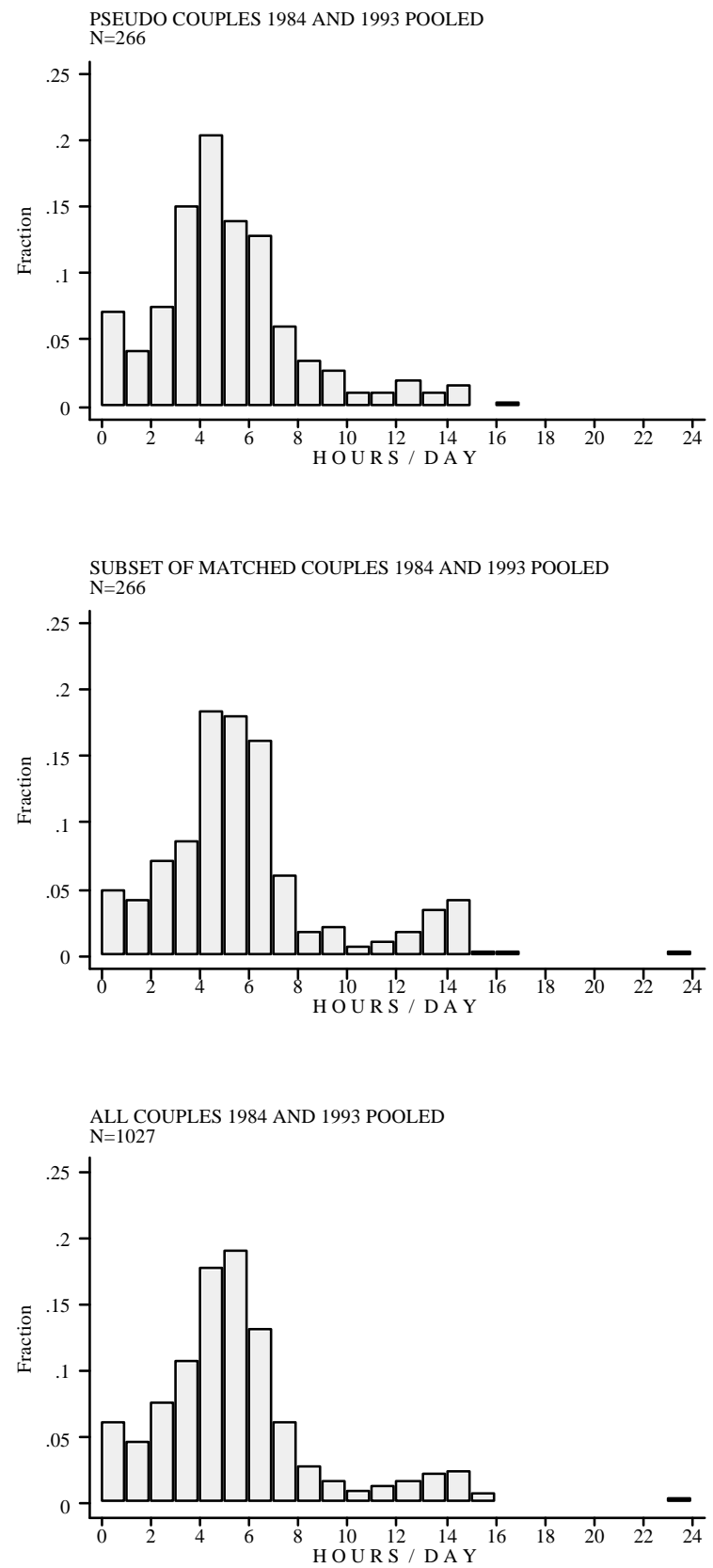

Figure 4: Hours of synchronous leisure (including household work) for pseudo couples (top), the subset of matched couples (middle), and all couples (bottom), 1984 and 1993 pooled. 
Since the matching is not perfect, some of the observed difference in synchronous leisure may result from compositional differences between groups. There are some dissimilarities between treated and controls with respect to covariates (see Section 4). A potential problem is that matched wives worked somewhat less than matched single women, since this may result in less synchronous leisure among the control couples. What seems to be an effect of behavioral differences between groups may instead be an effect of differences between groups.

It appears, however, that the compositional differences only explain a fraction of the observed difference in synchronous leisure $(S)$. Here, we estimated the composition effect by employing a Blinder-Oaxaca decomposition (see Blinder, 1973, and Oaxaca, 1973), shown in the bottom of Table $8 .^{19}$ The Blinder-Oaxaca decomposition can be interpreted as an evaluation of the matching. With perfect matching, the composition effect (with respect to matching variables) is zero. It is nonzero if the matching is imperfect as a result of differences between groups. For 1984, we find that between 9 and 40 percent of the total difference in $S$ can be attributed to differences in covariates, depending on the weighting scheme (see note in Table 8). In the second year, the composition effect lies somewhere between 27 and 31 percent, depending on the weighting scheme. Hence, the conclusion is that the main part of the observed differences in $S$ is explained by behavioral differences between groups and not by imperfect matching.

It might be argued that an alternative explanation for the observed treatment effect is that couples usually have better jobs and earn higher incomes than singles. Among the benefits usually associated with good positions is a high degree of flexible working hours. In

however, note that the outcome of $S$ for the matched samples is not very different from that for all couples (shown at the bottom of these figures).

19 The Blinder-Oaxaca decomposition procedure is to first estimate regression models for $S$ with matching variables (and a constant) as explanatory variables separately for each group. The composition effect is estimated by weighting the difference in the mean of the covariates between groups by the estimated coefficient vector belonging to either the first or the second group. A standard argument in the literature is that the true composition effect lies between these two weighting schemes. Note that the matching covariates that are household-specific variables for matched true couples (i.e. the number of children in different age brackets) were not restricted in the matching algorithm to be equal for a single man and a single woman matched together into a pseudo couple. The composition effect presented in the text is the average composition effect of first using the covariates of single males and then the covariates of single females. (The difference in the resulting composition effect, depending on which covariate vector was used is not very large, however). 
my data, there is a significant difference in the average taxable income for men taken from the sample of control units and the sample of treatment units (but not for women). ${ }^{20}$ To test the hypothesis that income differences (serving as a proxy for labor market position) explain differences in $S$, I run separate regressions for the samples by gender and year of $S$ on the yearly taxable income of each spouse, holding constant for the hours of market work of each spouse (not shown). ${ }^{21}$ The only significant effect of yearly taxable income found was that for single men in 1993. Those single men that earned more relative to other single men also had working schedules resulting in higher $S .^{22}$ I find no significant effect of yearly taxable income for the treatment group or for the original sample of all couples. The income difference between treatment units and control units should therefore result in a lower estimated treatment effect for high-income males in $1993 .^{23}$

\section{Time jointly with the spouse}

Some of the free time that spouses choose to consume simultaneously, they also choose to spend together. In this section, I will study the actual time that spouses spend with each other. The analysis in this section should perhaps best be seen as a study of welfare, since we think that the distribution of well-being depends on to what extent members in a society can interact and coordinate household work and leisure. These issues are of interest in view of

\footnotetext{
${ }^{20}$ The difference is statistically significant on 5 percent. In 1984 , single men in my sample earned about 74,000 SEK on an annual basis, while men in the subset of matched couples earned about 85,000 SEK. For 1993, the relative income difference had increased; single men earned 163,000 SEK on average and men in the subset of matched couples on average 191,000 SEK.

21 Income might be a bad proxy for the labor market position, considering that there may be a wage premium in jobs that offer less flexibility. On the other hand, it may mainly be low productivity individuals with low wage rates that accept jobs with low work time flexibility. Furthermore, income is a mixt ure of hours worked and hourly pay. It would be interesting to investigate if there are differences in $S$ with respect to hourly wage. Regrettably, there are too many missing observations in the hourly wage for singles.

22 The effect is not very large, however. For singles in 1993, the linear estimate on $S$ of an additional $10,000 \mathrm{SEK}$ in yearly taxable income for the single male is 0.066 ( $t$-ratio 3.29 ), i.e. approximately 4 minutes (the elasticity with respect to yearly taxable income is estimated to 0.20 percent).

${ }^{23}$ I have also tried to include the individual taxable income among my matching variables. The matching did not result in matched samples of single males and males in couples that were similar in taxable income, however.
} 
the changed labor market circumstances, above all the increased labor force participation by women in the Western World, including Sweden, in the past twenty years. How have these changes affected the spouses' capacity to synchronize their working schedules and enjoy more time together?

As for parents' time with children (see Hallberg and Klevmarken, 2002), it is reasonable that the decision to allocate time to the spouse is determined by both investment and consumption motives. To my knowledge, however, little or no theoretical results in the literature suggest how time allocated to the spouse varies with income and hourly wage. Couples that are economically better off (i.e. have a high income) might buy time with each other since they can afford certain costly services from the market (e.g., cooking and cleaning). It is reasonable to believe that highly productive individuals are more adept at planning, coordinating and streamlining their daily life. If there is a preference for togetherness, we might expect such couples to spend more time with the spouse than others. On the other hand, high productivity individuals may have a trade-off between many activities and after all, it is not certain that they spend more time with the spouse than low productivity individuals. It might even be less. Gronau and Hamermesh (2001) found substantial differences among households in the variety of nonmarket activities that they produce. By variety in activities, I mean the degree of variation in both types of activities and the number of activities performed. More educated individuals (who can also often be considered to be more productive) generate more variety, engaging in both additional activities and the same ones as the less educated. $^{24}$

It is, however, not certain that such considerations will influence the time-use together with the spouse. The event that spouses do spend time together, given that spouses have the opportunity to meet, might mainly depend on the extent of intra-household work burden and the cooperation of the spouses. For instance, parents of small children might prefer simultaneity but not necessarily togetherness in household work, since they must accommo-

\footnotetext{
24 This was found by studying activities recorded in time-use data from six countries (Australia, Israel, the Netherlands, Sweden, the United Kingdom and West Germany).
} 
date an explicit child care time constraint. While one spouse concentrate on, e.g., cooking a meal, the other takes care of the infant. The preference to be together should furthermore depend on how much spouses enjoy each other's company.

I will focus my empirical analysis in this section on how much of the potential time - in either leisure or household work - that spouses can be together $(S)$ is actually also spent together. Let $J$ denote the time that spouses actually are together. Accordingly, the variable of interest is $J / S$.

In the data-set used, the respondent was asked for each activity if someone else was present. One of the response alternatives was "spouse/common-law husband (wife)". ${ }^{25}$ Denote the individual response of total time spent with the spouse during a day by $J_{s}$, $s=m, f$. I define it as the total time during a day of either household work or leisure during which the spouse was reported present. The times when couples met at work and when the respondent was either sleeping or resting were excluded from the analysis. Sleep and rest are ignored to ensure that the two years are comparable. ${ }^{26}$ Market work is excluded to ensure consistency with the definition of synchronous leisure given in Section $4.2 .^{27}$

Some assumptions were needed to obtain a household measure of $J$ that is consistent with the definition of $S$. Because the spouses were interviewed separately 1) $J_{s}$ sometimes exceeds $S$, and 2) the responses of husband and wife usually differ, sometimes considerably. ${ }^{28}$

\footnotetext{
25 Other alternatives included being with one's own or spouse's/partner's child, other household members, other relatives, workmate/colleague, others, and being alone.

26 The original data for 1993 contain some sources of error. An explicit order was given to interviewers not to inquire about other persons being present during the activity sleep and rest. This order was followed in 1984 , but not strictly in 1993 .

27 Some couples meet at work, either because they work at the same place or because they work close to or actually in their homes (e.g. farmers), but these fractions are quite low. Neglecting time together during market work should not change the analysis in a significant way. About 85 percent report zero time and the average time for nonzero values is less than 1.3 hours per day in the whole sample of couples (pooling gender and years).
} 
,29 I will assume that the time that a respondent stated that he or she was together with the spouse is bounded by the time that the two spouses can potentially be together (i.e. by $S)$. I define the household measure of actual time that spouses were together as the average of the spouses' responses truncated at $S$ :

$$
J=\frac{\min \left(J_{m}, S\right)+\min \left(J_{f}, S\right)}{2} .
$$

Somewhat more than half the potential time (64 percent) was spent with the spouse. On average, spouses spent approximately 3.6 hours of a normal workday in each other's company out of 5.6 hours of simultaneous leisure and household work. This refers to the full sample of two-earner households, both years pooled. There is a small difference in means between years, but this is not significant. Only for very few households is $J$ zero $(31$ observations in 1984 and 17 in 1993).

The relationship that we will estimate is given by

$$
J / S=\alpha+\boldsymbol{\beta}^{\prime} \mathbf{x}+\varepsilon
$$

where $\alpha$ and $\beta$ are parameters and $\varepsilon$ is an error component. As explanatory variables I consider the husband's age, the age structure of the children, education (years of schooling and a dummy for university diploma), hourly wage rates net of taxes and incomes of the spouses. ${ }^{30}$ The division between market and nonmarket time may be more confusing for the self-employed than for others. I therefore also control for self-employment.

There might be interesting effects of economic variables on time together as suggested above. By including income and wage rates as explanatory variables, I test if couples'

\footnotetext{
$28 J_{s}$ can exceed $S$ if the respondent reported leisure or household work and stated that the spouse was present while the spouse reported market work or sleep - in which case the presence of the respondent is ignored - or reported leisure or household work but forgot that the respondent was actually present.

${ }^{29}$ In this respect, the disagreement between the husband's and the wife's response (total per day with the spouse in leisure or household work) is somewhat higher in 1993, as compared to 1984. An explanation for this might be that the design of the forms was changed between these years. The 1984 survey permitted combinations of two types of persons being present during an activity (spouse, child, other household members, work colleague, and others) and the 1993 survey permitted combinations of six types of persons.

${ }^{30}$ For simplicity, I will assume that the hourly wage rate after tax is exogenous. Income is taxable income measured on a yearly basis.
} 
economic possibilities have any direct effect on $J / S$. A recurrent suggestion in the literature is that individuals that are highly productive on the market also are highly productive at home. I will use the wage rate as a proxy for productivity. (Education may also capture this effect since it can be seen as a proxy for productivity too.)

Regression estimates of (5) are presented in Table 9 and Table 10 for 1984 and 1993, respectively. The estimation sample is the Monday-Friday responses from the whole sample of two-earner households. ${ }^{31}$ The husband's age is included as five dummy variables in 5 and 10-year age intervals with the reference category being 41-50 years of age. There are clearly systematical differences between families in how much time spouses spend together. We find that couples with small children and older couples consume significantly less time together than others. Young couples in their late 20s or early 30s without children spend most time together. In relation to the effect of children, however, the age effects dominate in size. However, the differences due to both age and children are smaller in the 1990s than in the 1980s.

There is also some weak support in the results that those with more years of schooling allocate less time to the spouse than others. Considering that education might function as a proxy for productivity, this effect might hence lend itself to an interpretation similar to that of Gronau and Hamermesh (2001). High productivity individuals more often have more activities from which to choose than other and evidently this decreases the time with the spouse. The effect is small, however, and only significantly different from zero at the 5 percent level in one of the three specifications for 1993, and at the 10 percent level in another specification for 1984 . We find a negative effect from the hourly wage rate of the husband in 1993, although significant only at the 10 percent level. Education variables are insignificant in that specification, which suggests that both the wage rate and the education variables seem to capture productivity to some extent. There is, however, no significant effect from the hourly wage rate in 1984 . Perhaps most of the expected effect of the wage variable is

\footnotetext{
31 The dependent variable is bounded between 0 and 1 , but $J / S$ is 0 (1) only for about 3 percent (about 10 percent). Tobit estimates (and $t$-statistics) are very similar to the OLS estimates presented in the text.
} 
Table 9: OLS estimates of the time with the spouse in relation to synchronous leisure and household work (J/S), 1984. (Full sample of two-earner households, Mon.-Fri.)

\begin{tabular}{|c|c|c|c|}
\hline & $\begin{array}{c}(1) \\
J / S\end{array}$ & $\begin{array}{c}(2) \\
J / S\end{array}$ & $\begin{array}{c}(3) \\
J / S \\
\end{array}$ \\
\hline \#children 0-2 & $-0.03(-0.69)$ & $-0.04(-0.77)$ & $-0.04(-0.98)$ \\
\hline \#children 3-6 & $-0.08(-2.79)^{* * *}$ & $-0.08(-2.57)^{* *}$ & $-0.10(-3.23)^{* * *}$ \\
\hline \#children 7-12 & $-0.01(-0.48)$ & $-0.02(-0.82)$ & $-0.01(-0.50)$ \\
\hline \#children 13-18 & $0.01(0.22)$ & $0.00(0.00)$ & $-0.00(-0.05)$ \\
\hline age $_{m} 18-25$ & $0.17(2.33)^{* *}$ & $0.16(1.82)^{*}$ & $0.18(2.37)^{* *}$ \\
\hline $\operatorname{age}_{m} 26-30$ & $0.17(2.87)^{* * *}$ & $0.18(2.97)^{* * *}$ & $0.20(3.40)^{* * *}$ \\
\hline $\operatorname{age}_{m} 31-40$ & $0.09(2.16)^{* *}$ & $0.11(2.25)^{* *}$ & $0.10(2.55)^{* *}$ \\
\hline $\operatorname{age}_{m} 51-60$ & $0.07(1.78)^{*}$ & $0.07(1.52)$ & $0.04(1.00)$ \\
\hline $\operatorname{age}_{m}$ 61- & $0.08(1.31)$ & $0.08(1.01)$ & $0.04(0.69)$ \\
\hline schooling $_{m}$ & $0.00(0.70)$ & $0.00(0.79)$ & $-0.00(-0.39)$ \\
\hline schooling $_{f}$ & $-0.01(-1.83)^{*}$ & $-0.01(-1.20)$ & $-0.01(-1.30)$ \\
\hline university $_{m}$ & $-0.08(-1.55)$ & $-0.08(-1.37)$ & $-0.08(-1.59)$ \\
\hline university $_{f}$ & $0.06(1.12)$ & $0.05(0.79)$ & $0.06(1.06)$ \\
\hline self-employed ${ }_{m}$ & $0.03(0.92)$ & $-0.06(-0.88)$ & $0.05(1.29)$ \\
\hline self-employed $_{f}$ & $-0.06(-1.15)$ & $-0.08(-0.49)$ & $-0.07(-1.19)$ \\
\hline$W_{m} / 10^{2}$ & & $-0.38(-1.42)$ & \\
\hline$W_{f} / 10^{2}$ & & $-0.13(-0.48)$ & \\
\hline$Y_{m} / 10^{5}$ & & & $0.07(1.86)^{*}$ \\
\hline$Y_{f} / 10^{5}$ & & & $-0.02(-0.42)$ \\
\hline Constant & $0.68(10.97)^{* * *}$ & $0.74(7.26)^{* * *}$ & $0.66(9.69)^{* * *}$ \\
\hline Observations & 497 & 369 & 466 \\
\hline $\mathrm{R}^{2}$ & 0.06 & 0.08 & 0.08 \\
\hline
\end{tabular}

Note: Robust $t$-statistics in parentheses. $*, * *, * * *$ significant at 10,5 and 1 percent, respectively. $W$ is the hourly wage rate after tax. $Y$ is the yearly taxable income. 
Table 10: OLS estimates of the time with the spouse in relation to synchronous leisure and household work (J/S), 1993. (Full sample of two-earner households, Mon.-Fri.)

\begin{tabular}{|c|c|c|c|}
\hline & $\begin{array}{c}(1) \\
J / S\end{array}$ & $\begin{array}{c}(2) \\
J / S\end{array}$ & $\begin{array}{c}(3) \\
J / S\end{array}$ \\
\hline \#children 0-2 & $-0.05(-1.06)$ & $-0.08(-1.25)$ & $-0.04(-0.77)$ \\
\hline \#children 3-6 & $-0.04(-1.52)$ & $-0.06(-1.72)^{*}$ & $-0.04(-1.20)$ \\
\hline \#children 7-12 & $-0.05(-2.28)^{* *}$ & $-0.06(-2.30)^{* *}$ & $-0.04(-1.76)^{*}$ \\
\hline \#children 13-18 & $-0.01(-0.60)$ & $-0.04(-1.85)^{*}$ & $-0.01(-0.48)$ \\
\hline age $_{m} 18-25$ & $-0.06(-0.69)$ & $-0.11(-1.00)$ & $-0.03(-0.32)$ \\
\hline age $_{m} 26-30$ & $0.04(0.74)$ & $0.02(0.34)$ & $0.08(1.51)$ \\
\hline age $_{m} 31-40$ & $0.07(1.71)^{*}$ & $0.10(2.50)^{* *}$ & $0.09(2.10)^{* *}$ \\
\hline $\operatorname{age}_{m} 51-60$ & $-0.06(-1.81)^{*}$ & $-0.09(-2.25)^{* *}$ & $-0.05(-1.45)$ \\
\hline $\mathrm{age}_{m}$ 61- & $-0.03(-0.67)$ & $-0.08(-1.15)$ & $-0.02(-0.42)$ \\
\hline schooling $_{m}$ & $-0.01(-1.19)$ & $-0.00(-0.04)$ & $-0.01(-2.03)^{* *}$ \\
\hline $\operatorname{schooling}_{f}$ & $0.00(0.73)$ & $0.00(0.50)$ & $0.00(0.37)$ \\
\hline university $_{m}$ & $0.04(0.98)$ & $0.02(0.37)$ & $0.05(1.04)$ \\
\hline university $_{f}$ & $-0.05(-1.39)$ & $-0.07(-1.51)$ & $-0.06(-1.50)$ \\
\hline self-employed $_{m}$ & $0.08(2.36)^{* *}$ & $0.06(0.97)$ & $0.12(3.13)^{* * *}$ \\
\hline self-employed $_{f}$ & $0.06(1.23)$ & $0.12(1.57)$ & $0.02(0.41)$ \\
\hline$W_{m} / 10^{2}$ & & $-0.09(-1.82)^{*}$ & \\
\hline$W_{f} / 10^{2}$ & & $0.09(0.79)$ & \\
\hline$Y_{m} / 10^{5}$ & & & $0.04(2.65)^{* * *}$ \\
\hline$Y_{f} / 10^{5}$ & & & $0.04(1.85)^{*}$ \\
\hline Constant & $0.72(9.15)^{* * *}$ & $0.70(6.99)^{* * *}$ & $0.65(7.63)^{* * *}$ \\
\hline Observation & 508 & 372 & 454 \\
\hline $\mathrm{R}^{2}$ & 0.05 & 0.07 & 0.06 \\
\hline
\end{tabular}

Note: See Table 9. 
captured by education. ${ }^{32}$

The results also suggest that a couple with high incomes in 1993 spent more time of $S$ together than those with low incomes. If translating these effects into elasticities, we can conclude that a 10 percent higher income of one of the spouses is coupled with a 1 percent increase in togetherness at a given level of synchronous leisure and household work. The null that the effect on $J / S$ of the husband's income and the wife's income are equal is not rejected by an F-test, which suggests that the source of income is of no importance in this case. One interpretation of this effect could be that high-income couples choose to buy costly market services that free time for togetherness. In 1984, the effect of the husband's individual income was positive and significant, but only at the 10 percent level. This, and the result that the point estimate of the wife's income in 1984 is negative, although insignificant, suggests that the income effect for 1993 should be interpreted with great caution. Finally, we note that the presented regression estimates explain only a small fraction of the total variation in the dependent variable.

\section{Summary and concluding remarks}

This paper examines the temporal choices of time-use and the time spouses spend together. As suggested by Hamermesh (2000), it is plausible to think that couples seek to maximize their joint time. Thus, couples must constantly adjust the timing of their activities to one another, especially market work.

Swedish time budget data from 1984 and 1993 are used to study this issue. The results give empirical support for the timing of spouses being strongly dependent between spouses. If one of the spouses performs market work in a daytime hour, the other spouse it is more likely to also do this than not. Spouses also organize the timing of leisure so that it is enjoyed at the same time. Timing dependence is less frequent in household work and sleep

\footnotetext{
32 Because there is a compression in the after tax wage rate introduced by the progressiveness in the tax system, one might consider using the before-tax wage rate instead, since it better captures individual productivity. However, alternative specifications with the gross wage rate did not result in significant effects either.
} 
as compared to leisure, however.

I perform a matching experiment using a sample of singles as a control group for a sample of true couples, to assess the effect of spouses' timing coordination. I show that the observed outcome in timing is, to some extent, a result of the proposed coordination in timing and to some extent a result of the general organization of society. The results suggest that by coordinating work and leisure hours, couples obtain about 12 percent (three quarters of an hour) additional synchronous leisure than would otherwise have been the case. The effect of coordination is hence not very large, although statistically significant, and essentially the same during the whole study period.

The data set used in this paper allows for a distinction between simultaneous time-use of the spouses and the actual time that spouses meet. I find that the time that spouses spend together, conditional on the time that spouses can potentially meet, depends negatively on the presence of small children. Togetherness is low among older couples as compared to younger couples. We also find some support for the hypothesis that more educated individuals allocate less time to their spouse than those who are less educated. This effect is weak and only marginally significantly different from zero, however. Furthermore, there are some indications that, at least in the 1990s, high-income spouses spent more time together, given the potential time that they could meet. One interpretation might be that couples that are economically better off are able to buy costly market services that free time for togetherness.

Traditional models of time-use usually overlook the timing aspect of time-use. The main conclusion of the findings in this paper is therefore that traditional models potentially miss a vital part of behavior. Individuals' use of time should not in general be summarized over a long period of time and then studied as an aggregate. The finding that timing is essential for individual behavior implies that a reasonable micro-economic model of time-use should also incorporate this dimension, or at least test whether or not the timing mechanism is of importance. 


\section{References}

Blinder, A. (1973), "Wage discrimination: Reduced Form and Structural Estimates," Journal of Human Resources, 18:4, pp. 436-455.

Flood, L., N.A. Klevmarken, and P. Olovsson (1996), "Household Market and Nonmarket Activities (HUS), volumes III-VI," Department of Economics, Uppsala University.

Goodman, L. A. and W. H. Kruskal (1954), "Measures of Association to Cross Classifications," Journal of the American Statistical Association, 49.

Flood, L., N.A. Klevmarken and P. Olovsson (1996), "Household Market and Nonmarket Activities (HUS), volumes III-VI", Department of Economics, Uppsala University.

Gronau, R. and D. Hamermesh (2001), "The Demand for Variety: A Household Production Perspective," NBER Working Paper 8509.

Hallberg, D. and A. Klevmarken (2002), "Time for Children: A Study of Parents' Time Allocation," Forthcoming in Journal of Population Economics.

Hamermesh, D. (1998),"When We Work," The American Economic Review, Vol. 88, Iss. 2, pp. 321-325 (Papers and Proceedings).

Hamermesh, D. (1999), "The Timing of Work over Time," The Economic Journal, 109 (January), pp. 37-66.

Hamermesh, D. (2000), "Togetherness: Spouses' Synchronous leisure, And the impact of Children," NBER Working Paper 7455.

Killingsworth, M. and J. Heckman (1986), "Female Labor Supply: A Survey," in Handbook of Labor Economics, Vol. 1 (Chapter 2), Edited by O. Aschenfelter and R. Layard, Elsevier Science Publishers BV.

Klevmarken, A. and P. Olovsson (1993), "Household Market and Nonmarket Activities, Procedures and Codes 1984-1991," The Industrial Institute for Economic and Social Research.

Kooreman, P. and S. Wunderink (1996), The Economics of Household Behavior, Houndmills, Basingstoke, Hampshire/London: Macmillian Press Ltd.

Moore, W. E. (1963), Man, Time, and Society, New York/London: John Wiley and Sons.

Oaxaca, R. (1973), "Male Female Wage Differentials in Urban Labor Markets," International Economic Review, 14:3, October, pp. 693-709. 
Rubin, D. B. (1979), "Using Multivariate Matched Sampling and Regression Adjustment to Control Bias in Observational Studies," Journal of the American Statistical Association, Vol 74, Issue 366, pp 318-328.

Rydenstam, K. and A. Wadeskog (1995), "Vardagens organisation," (The Organization of Everyday Life) offprint from "Välfärd och ojämlikhet $i$ 20-årsperspektiv 1975-1995, Levnadsförhållanden," (Taking a 20 Year View of Welfare and Inequality, 1975-1995) SCB Rapport 91, SCB, pp 95-104.

SCB (1999), "Arbetsmiljöundersökningen 1999" ("The Work Environment 1999"), AM 68 SM 0001.

StataCorp. (1999), "Stata Statistical Software: Release 6.0.," College Station, TX: Stata Corporation, Stata Reference Manual, Release 6, Vol. 4, Su-Z, pp. 172.

Sullivan, O. (1996), "Time Co-ordination, The Domestic Division of Labour and Affect Relations: Time-use and the Enjoyment of Activities Within Couples," Sociology, Vol. 30:1 (Feb.), pp. 79-100.

Velzen, S. van (2001), "Synchronizing Rhythms of Work and Leisure; an Analysis of the Timing of Market work, Household Work, and Leisure of Dual-earner Couples in the Netherlands," Essay III in Supplements to the Economics of Household Behavior, Doctoral Dissertation 242, Tinbergen Institute Research Series, University of Amsterdam, pp. $99-127$. 


\section{Appendix}

The algorithm below will simultaneously match a single male to a single woman with a pseudo couple and this pseudo couple to a real couple ("double matching"). The matching obtains a control group of pseudo couples $M_{0}$ and a treatment group of real couples $M_{1}$. The matching is made without replacement. The matching technique is outlined in Rubin (1979). Denote the random samples of single males and single females by $G_{0 m}$ and $G_{0 f}$, with sample sizes $N_{0 m}$ and $N_{0 f}$, respectively. Let $G_{1}$ be the sample of true couples with sample size $N_{1}$. Denote the sorted samples of males in a couple and females in a couple by $G_{1 m}$ and $G_{1 f}$, respectively. Here $N_{0 m}<N_{1}$, and $N_{0 f}<N_{1}$. Since matching is made without replacement, the matched samples $M_{0}$ and $M_{1}$ will each consist of $\min \left(N_{0 m}, N_{0 f}\right)$ observations. Consider a set of $k$ matching variables for each individual in each sample, denoted $x_{q s j}$, where $q$ indexes single samples (0) or couple samples $(1), s$ indexes male $(m)$ or female $(f)$ and $j=1, \ldots, N_{q s}$ indexes observation. First estimate the pooled within-sample covariance matrix of $\mathbf{X}$ based on the random samples $G_{0 s}$ and $G_{1 s}$, i.e.

$$
\mathbf{z}_{s}=\left[\left(\mathbf{X}_{0 s}^{\prime} \mathbf{X}_{0 s}-N_{0 s} \overline{\mathbf{x}}_{0 s}^{\prime} \overline{\mathbf{x}}_{0 s}\right)+\left(\mathbf{X}_{1 s}^{\prime} \mathbf{X}_{1 s}-N_{1 s} \overline{\mathbf{x}}_{1 s}^{\prime} \overline{\mathbf{x}}_{1 s}\right)\right]\left(N_{0 s}+N_{1}-2\right)^{-1}, s=m, f,
$$

where $\mathbf{X}_{m s}$ is the $N_{q s} \times k$ data matrix of $\mathbf{X}$ in $G_{q s}$ and $\overline{\mathbf{x}}_{q s}$ is $1 \times k$ sample mean vector. Second, sort the sample of single males $\left(G_{0 m}\right)$ randomly. Then, proceed with the following matching algorithm:

(1) Take single male $g$ in $G_{0 m}$ and compute for every $j=1, \ldots, N_{0 f}$, and $i=1, \ldots, N_{1}$,

$$
V_{j i}=\left(\mathbf{x}_{0 m g}-\mathbf{x}_{1 m i}\right) \mathbf{z}_{m}^{-1}\left(\mathbf{x}_{0 m g}-\mathbf{x}_{1 m i}\right)^{\prime}+\left(\mathbf{x}_{0 f j}-\mathbf{x}_{1 f i}\right) \mathbf{z}_{f}^{-1}\left(\mathbf{x}_{0 f j}-\mathbf{x}_{1 f i}\right)^{\prime}
$$

Each term in $V_{j i}$ is the Mahalanobis metric - the distance between a $G_{0 s}$ unit with score $\mathbf{x}_{0 s}$ and a $G_{1 s}$ unit with score $\mathbf{x}_{1 s}$ - for the male $(s=m)$ and the female $(s=f)$.

(2) The best matching for the single male $g$ is the combination of $j$ and $i$ with the lowest $V_{j i}$. Move that combination of $g, j$ and $i$ from $G_{0 m}, G_{0 f}$, and $G_{1}$ into the matched samples $M_{0}=\left[\begin{array}{ll}M_{0 m} & M_{0 f}\end{array}\right]$ and $M_{1}$, respectively.

(3) Take the next single male and repeat steps 1 and 2 until $G_{0 m}$ or $G_{0 f}$ are empty. 